Bond University

Research Repository

\title{
Lifting the Numbers Game: Identifying key input variables and a best-performing model to detect financial statement fraud
}

Gepp, Adrian; Kumar, Kuldeep; Bhattacharya, Sukanto

Published in:

Accounting and Finance

DOI:

10.1111/acfi. 12742

Licence:

Other

Link to output in Bond University research repository.

Recommended citation(APA):

Gepp, A., Kumar, K., \& Bhattacharya, S. (2021). Lifting the Numbers Game: Identifying key input variables and a best-performing model to detect financial statement fraud. Accounting and Finance, 61(3), 4601-4638. https://doi.org/10.1111/acfi. 12742

\section{General rights}

Copyright and moral rights for the publications made accessible in the public portal are retained by the authors and/or other copyright owners and it is a condition of accessing publications that users recognise and abide by the legal requirements associated with these rights.

For more information, or if you believe that this document breaches copyright, please contact the Bond University research repository coordinator 


\title{
Lifting the Numbers Game: \\ Identifying key input variables and a best-performing model to detect financial statement fraud
}

\section{Adrian Gepp, Kuldeep Kumar, Sukanto Bhattacharya}

\begin{abstract}
This study enables practitioners and researchers to make an informed choice for a financial statement fraud detection model, rather than defaulting to popular, yet dated, models. Using a specifically devised performance criterion, our newly configured ensemble outperforms 31 others in the most comprehensive comparison to date spanning parametric, non-parametric, big data and ensemble techniques. We use a large set of input variables and holdout data relative to prior studies. We find empirical support for financial and non-financial variables covering the three Fraud Triangle factors. New findings include fraud risk being reduced with more debt, likely from increased monitoring by creditors.
\end{abstract}

This is the peer reviewed version of the following article: Gepp, A., Kumar, K., \& Bhattacharya, S. (2020). Lifting the Numbers Game: Identifying key input variables and a best-performing model to detect financial statement fraud. Accounting and Finance, which has been published in final form at https://doi.org/10.1111/acfi.12742. 
The cost of financial statement fraud continues to increase and could be exceeding 1.15 trillion US dollars worldwide, every year ${ }^{1}$. Contrary to a commonplace notion, financial statement fraud is not a victimless crime as its cost is ultimately borne by individuals and the society at large, as direct or indirect stakeholders in the fraudulent companies. Investors and financiers are the most direct victims as they provide funds to the company under false pretences and will likely not ever recover their money (KPMG Forensic 2012). Many employees also lose their jobs because of excessive hiring during fraud schemes (Kedia and Philippon 2009). There are also wider costs to society at a macro level, such as a reduction of confidence in the financial systems (Dechow et al. 2011), although the economic effect at the firm level can be variable (Tan, Chapple, and Walsh 2015).

Many business decisions rely on the accuracy of financial statements, but resources are not available to comprehensively investigate all of them. Moreover, penalties facing perpetrators of fraud are not a sufficient deterrent under many regulatory jurisdictions (Beasley et al. 2010; Partnoy 2010). Evidence also suggests auditors perform poorly at detecting financial statement fraud and should not be relied upon for it (ACFE 2018). To make matters worse, as perpetrators become more proficient in evading regulatory oversight, fraud is growing in complexity (Dorminey et al. 2012). Consequently, there is a need for better auditor decision support tools to detect and deter these frauds (Humpherys et al. 2011). Quantitative approaches to financial statement fraud detection can estimate the likelihood of fraud occurrence via statistical analysis of key financial ratios and other variables, which can be used to make an informed determination as to whether an expensive and resourceintensive forensic investigation is warranted, often well before an official disclosure by the regulator (Beasley et al. 2010; Karpoff et al. 2017). A reliable estimation of fraud occurrence likelihood can thus be used to improve early detection, which would mitigate the costs of fraud and help deter potential future perpetrators.

For maximum practical effectiveness, reliable financial fraud detection models should be available in an easy to use format not only to auditors, but also to equity investors, creditors, regulators and other stakeholders, as auditors have been found complicit in several cases of financial statement fraud (Beasley et al. 2010). However, extant research on quantitative approaches in financial fraud detection is largely focused on the banking and financial services sector, particularly on the detection of insurance and credit card fraud. There is

\footnotetext{
${ }^{1}$ The ACFE (2018) estimated an annual total fraud loss of approximately 4 trillion dollars, as well as providing the median cost and relative frequency per fraud category (including financial statement fraud). As means were not reported, the ratios of mean costs were assumed to be the same as for the median costs.

This is the peer reviewed version of the following article: Gepp, A., Kumar, K., \& Bhattacharya, S. (2020). Lifting the Numbers Game: Identifying key input variables and a best-performing model to detect financial statement fraud. Accounting and Finance, which has been published in final form at https://doi.org/10.1111/acfi.12742. 
relatively little research featured in reputable academic journals on quantitative approaches to detect and deter financial statement fraud. Further, the little research that exist uses relatively small data sets (Phua et al. 2010). A further practical shortcoming is the lack of applicability across a very wide range of financial statement fraud scenarios cutting across different stakeholders, direct as well as indirect. Parametric approaches like logistic regression, because of their innate dependence on underlying restrictive distributional assumptions, lack universal applicability that non-parametric approaches can offer. This dearth of research on a reliable nonparametric approach to financial statement fraud detection drives the motivation for this paper. Further, as priorities vary between stakeholders, we devised a cost-based metric to evaluate model performance. Our posited ensemble model combining parametric and non-parametric approaches outperforms all other alternative approaches in its prediction performance.

For quantitative financial statement fraud detection approaches to be reliable, a lot depends on the input variable selection. This is much like what is seen in the related domain of quantitative approaches to business failure prediction, that has a comparatively richer literature mainly spurred by the ground-breaking work of Altman (1968). Accordingly, we have carefully identified a large pool of financial ratios and other numeric variables as potential inputs, some well-known and some not considered before in a similar exercise. As a direct contribution to the extant financial auditing and forensic accounting literature, we analyse which variables offer the highest informational utility to financial statement fraud detection. Moreover, while most existing studies evaluate only a single method or scenario, we consider a variety of scenarios likely faced by stakeholders in reality, thus increasing the practical value to auditors and forensic accountants of our findings about variables and models that are useful for fraud detection.

The remainder of this paper is structured as follows. A brief review of the extant literature is presented next, culminating in the main research questions. and the key research questions. Subsequently, the data and methodology are presented, including the variable identification process based on prior literature. The results are then discussed before the conclusion that summarises the major contributions, recognises the limitations and offers some interesting future research directions.

\subsection{Brief literature review to identify current gaps in the financial fraud detection literature}

The most relevant prior studies reported in forensic accounting literature are deemed to be those that have used publicly available US data as done in this study. These studies are summarized in Table 1 for ease of visual inspection. For a more extensive coverage of studies that use other data sources, develop alternative theoretical

This is the peer reviewed version of the following article: Gepp, A., Kumar, K., \& Bhattacharya, S. (2020). Lifting the Numbers Game: Identifying key input variables and a best-performing model to detect financial statement fraud. Accounting and Finance, which has been published in final form at https://doi.org/10.1111/acfi.12742. 
frameworks and detect other types of financial frauds, interested readers are directed to two relevant review articles (Gepp et al. 2018; Ngai et al. 2011).

[insert Table 1 approximately here]

Prior literature has reported several ratios and other numeric variables computed from financial statements to be statistically significant in detecting financial statement fraud. Details of variable selection based on the relevant literature are separately presented in subsequent sections as this is a key contribution this paper makes to the literature on forensic accounting in general and financial statement fraud detection in particular.

Apart from variable identification, this paper makes another key theoretical contribution to literature by way of devising and using a specific cost-based performance metric for comparing between alternative quantitative approaches to detect financial statement fraud. By analysing prior studies, two important considerations when evaluating the prediction performance of fraud detection models have been identified.

1. Model performance is overestimated if it is tested on the training data that were used to develop the model as has been done in some studies as shown by a "No" in the "Test Data" column of Table 1. Holdout test data are preferred (Sutton 2005), ideally partitioned chronologically because these result in more realistic accuracy estimates as models are tested on data further into the future. When the data set is too small to have a separate holdout sample, cross-validation is preferable (Sutton 2005).

2. It is very important to consider both types of misclassification errors that models can make:

- Missing fraud is costly in terms of stakeholders being misled into making decisions using fraudulent information, such as investing in a fraudulent company.

- Falsely alleging fraud is also costly in terms of lost investment opportunities, wasted investigatory time and money, and damage to misclassified businesses.

While it is generally agreed that the first error is more costly than the second, a quantifiable difference in the error costs has not been, and is unlikely to be, agreed upon since it varies depending on the stakeholder (Beneish 1999a). Consequently, research considering a range of error-cost ratios is desirable (Ngai et al. 2011). Assessing models using a performance measure such as a weighted cost of errors is superior to studying the percentage accuracy, which incorrectly assumes equal costs. An alternative performance measure is called the area under the ROC curve, which averages performance over all possible ratios of error costs. Nevertheless, using the cost of errors is still preferred, because the area under the ROC curve is not methodologically appropriate for this

This is the peer reviewed version of the following article: Gepp, A., Kumar, K., \& Bhattacharya, S. (2020). Lifting the Numbers Game: Identifying key input variables and a best-performing model to detect financial statement fraud. Accounting and Finance, which has been published in final form at https://doi.org/10.1111/acfi.12742. 
purpose (Perols 2011) and it has also been argued to be inadequate for model comparison purposes (Hand 2009a; Hand 2009b).

Standard regression-based techniques, including discriminant analysis and particularly logistic regression, have been widely studied for detecting financial statement fraud and are therefore excellent benchmarks for a comparative study. The best-known specific models are the M-score (Beneish 1997, 1999a) and F-score (Dechow et al. 2011), both of which have been included in this study. In terms of non-parametric approaches, artificial neural networks (ANNs) have often been applied to financial statement fraud detection (Green and Choi 1997). While backpropagation networks with one hidden layer have been the most common configuration, optimizing the parameters of ANNs with evolutionary algorithms (derived from Darwinian principles) has also shown promise (Fanning and Cogger 1998; Busta and Weinberg 1998; Bhattacharya, Xu, and Kumar 2011). However, there is a shortage of studies that evaluate ANNs over a range of error-cost ratios and that empirically optimize the cut-off values for classification (see Section 2.3.5). This is identified as a research gap and ANNs have therefore been included to test their performance over a range of error-cost ratios.

Decision trees are another non-parametric alternative. However, there is a lack of research that uses decision trees, particularly CART (Breiman et al. 1984) that has been shown to be superior to other decision-tree techniques when applied to other classification problems in business (Gepp, Kumar, and Bhattacharya 2010). Consequently, CART decision trees have been used in this study to address this research gap.

Overall, there is a paucity of research involving more than a hundred identified fraud cases. This issue is important as the size of the data set has implications for the ability of models to distinguish between fraudulence and legitimacy, and the accuracy of performance measurements. Consequently, using larger data sets would be valuable, which is another aspect on which this study stands apart from previous ones.

Studies that compare a variety of techniques are also relatively scarce, but those that exist indicate that ensembles such as Random Forests and stochastic gradient boosting perform relatively well at detecting financial statement fraud. Ensembles combine the results of multiple underlying models. This research evaluates ensembles using a much larger training and holdout sample relative to previous studies. There is some confusion in past reported results, particularly around unexplained poor performance of ensembles, decision trees and ANNs (Perols 2011). This research provides insights on this issue by re-testing those models, again using a larger data set comprising more identified fraud cases and also a larger holdout sample.

This is the peer reviewed version of the following article: Gepp, A., Kumar, K., \& Bhattacharya, S. (2020). Lifting the Numbers Game: Identifying key input variables and a best-performing model to detect financial statement fraud. Accounting and Finance, which has been published in final form at https://doi.org/10.1111/acfi.12742. 


\section{Research Questions}

There are three research questions this paper examines.

Research Question 1 (RQ1) What model is the best overall at detecting financial statement fraud, under varying assumptions about the prior probability of fraud and error cost ratios?

This identifies the best off-the-shelf quantitative approach available to academics and practitioners in financial statement fraud detection applications across a large range of possible scenarios. Whether there is a benefit to using a model tailored to a specific scenario is investigated next.

Research Question 2 (RQ2) With regard to informed stakeholders who can estimate their specific error cost ratio and the prior probability of fraud, can they benefit from a tailored model instead of the best overall model from RQ1?

A key contribution of this research is how it considers both numerous ratios of error costs and a range of prior fraud probabilities based on prior literature. This is necessary because the ratios of error costs can vary substantially between different stakeholders, and the true priors are unknown and estimates vary in the literature. The results from exploring RQ2 reveal the best-performing quantitative approach for detecting financial statement fraud for each scenario and how each compares to the general off-the-shelf approach from RQ1.

For quantitative fraud detection, a million-dollar question is of course about identifying and selecting appropriate input variables that carry the maximum informational utility to attain the most accurate out-ofsample predictions. This motivates our final research question.

Research Question 3 (RQ3) Which explanatory variables are the most useful in models that detect financial statement fraud?

For the purpose of this paper, variables that were statistically significant in prior research were included in an initial set of input variables, which is more comprehensive than used in prior studies. A few new variables are also included, based on fraud examination practice and research from the broader discipline of accounting. Variables are also justified with reference to the Fraud Triangle, the dominant framework in fraud examination (Free 2015). The Fraud Triangle was popularised by Joseph Wells (Morales, Gendron, and Guénin-Paracini 2014) and based on the much earlier work of Cressey (1953). The three factors (vertices) of the Fraud Triangle represent the key drivers of fraud: an opportunity $(\mathrm{O})$ to commit fraud, a pressure $(\mathrm{P})$ to commit fraud and a rationalisation $(\mathrm{R})$ for committing fraud that is consistent with the perpetrator's ethics as depicted in Figure 1.

Figure 1. The Fraud Triangle framework.

[insert Figure 1 approximately here]

This is the peer reviewed version of the following article: Gepp, A., Kumar, K., \& Bhattacharya, S. (2020). Lifting the Numbers Game: Identifying key input variables and a best-performing model to detect financial statement fraud. Accounting and Finance, which has been published in final form at https://doi.org/10.1111/acfi.12742. 
This study focuses on public companies listed on US stock exchanges. The Over-The-Counter (OTC) markets have been excluded because there is less data transparency and availability, and a lack of required standards for companies listing on them (SEC). The data were also restricted to publicly listed companies in order to be consistent with the aim to produce research findings that will be widely applicable to various stakeholders.

Imbalanced data have been recently shown (Veganzones and Séverin 2018) to have a substantial effect on similar classification exercises; Ngai et al. (2011) have called for more research to consider the cost imbalance issue. Hence, a balanced data set has been used (see Section 2.1.1), and the performance metric developed duly caters for the fact that the population data and misclassification error costs are both imbalanced (see Section 2.3). Furthermore, cut-off values for the classification models are empirically optimized on training data to adjust for imbalanced data and varying cost ratios as influenced by different stakeholder priorities.

\subsection{Data}

It is important to establish benchmark data sets to promote comparability between studies. Dechow et al. (2011) provide details on such a data set, which has been constructed from allegations of financial statement fraud by the US Securities and Exchange Commission (SEC) and disclosed in Accounting and Auditing Enforcement Releases (AAERs). This data set is used for this research. Even though these are only cases of alleged fraud, they will simply be referred to as cases of fraud in order to simplify the text.

AAERs are the most popular resource for empirical studies on financial statement fraud. SEC enforcement actions are publicly available, unlike data held by auditing firms that are rarely made available for research (Fanning and Cogger 1998). AAERs are one of the most comprehensive sources of detected cases of fraud (Karpoff et al. 2017) and no better publicly available source exists (Beasley et al. 2010). The SEC has limited resources and so is most likely to pursue cases that have a greater assurance of fraud and less ambiguity (Dechow, Ge, and Schrand 2010). As a result, the reliability of SEC allegations is very high, meaning that financial statements alleged to be fraudulent are highly unlikely to be legitimate. The fact that there are minimal disputes of SEC allegations also supports this claim.

While there is little risk from false identification of fraudulent cases, there is no doubt that the SEC misses some frauds (Dyck, Morse, and Zingales 2013; Karpoff et al. 2017) on account of limited resources.

This is the peer reviewed version of the following article: Gepp, A., Kumar, K., \& Bhattacharya, S. (2020). Lifting the Numbers Game: Identifying key input variables and a best-performing model to detect financial statement fraud. Accounting and Finance, which has been published in final form at https://doi.org/10.1111/acfi.12742. 
Consequently, there is a risk that when choosing legitimate observations a truly fraudulent observation may be selected, even though there is no AAER issued against it. Unfortunately, it is mostly an unavoidable problem with this type of research and it highlights the importance of not training overly-complex models that become too specific to the training data, which itself may contain errors. Nevertheless, the SEC likely focuses on the largest and costliest fraud cases in accordance with its duty to protect investors. This bias towards the costliest frauds is arguably a benefit for detection models. Additionally, a bias towards SEC alleged fraud is very informative because an SEC investigation is a very important event for any company (Beasley et al. 2010).

Consistent with previous research, the data used in this study cover a wide range of industries and fraud is fairly uniformly distributed across the range of business sizes. This suggests that models developed from such data are applicable to a broad range of companies in terms of their size and industry representation.

\subsubsection{Selection of Matching Legitimate Observations}

As in the majority of prior studies, the legitimate cases were selected using a one-to-one matched-pairs design, because it controls for external and unobservable factors (Fanning and Cogger 1998; Johnson, Ryan, and Tian 2009) and avoids bias towards one particular classification which may increase their discriminating ability (Persons 1995; Alden et al. 2012).

Matching based on year, industry and size is commonplace to limit unwanted signals from seasonal earning patterns, unique industry effects and company size. Matching was also performed on company age as undertaken in previous research (Beneish 1999b; Desai, Hogan, and Wilkins 2006; Perols and Lougee 2011) because the SEC is thought to perceive younger companies to have a higher likelihood of financial statement fraud (Beneish 1999b). Matching has also been performed according to the stock exchange the fraudulent company is listed on (Beasley 1996; Abbott, Parker, and Peters 2004; Beasley et al. 2010) to control for differences in reporting requirements between exchanges. In summary, matched legitimate companies were chosen based on their:

- Existence in the specified year (Year);

- Being from the same industry according to two-digit SIC codes (Industry);

- Listing on the same stock exchange and reporting in US dollars (Exchange);

- Being in the same age range: over ten years old, five to ten years old and younger than five years (Age). This criterion was progressively relaxed if an initial match was not found;

- Having the closest (non-zero and non-blank) size according to total assets (Size); and,

- Not having financial statements alleged to be fraudulent in any AAER in the sample period.

This is the peer reviewed version of the following article: Gepp, A., Kumar, K., \& Bhattacharya, S. (2020). Lifting the Numbers Game: Identifying key input variables and a best-performing model to detect financial statement fraud. Accounting and Finance, which has been published in final form at https://doi.org/10.1111/acfi.12742. 
For each company that produced fraudulent statements in consecutive years, a matching legitimate company is found for the first fraud year and then that same match is used for the subsequent years.

\subsubsection{Selection of the Time Period to Study}

In order to include a larger number of frauds relative to prior studies, a ten-year time period from 1998 to 2007 was chosen. More recent data were not used because there is a long, multiple-year lag between the occurrence of the fraud and its disclosure in an AAER (Beasley et al. 2010; Karpoff et al. 2017). There is further evidence to support choosing 2007 as the endpoint, because there is major concern that the years that follow are still incomplete in the benchmark data set used. This is because 2008 to 2010 are the only years in the data set that have more than a $50 \%$ decline in the number of frauds from the year prior. This is in stark contrast to the expectation of increased fraud during that period of economic decline (Rezaee and Riley 2010). The long lag between fraud and AAER release also points to the need for models to speed up the detection.

\subsubsection{The Final Data Set}

The final data set is described in Table 2 and is chronologically partitioned for more realistic accuracy estimates as per the review in Section 1.1. The number of fraud cases is substantially greater than in most prior studies, and is often more than double that used previously. This large number of fraud cases is vital as it increases the validity of evaluations and comparisons. Having more data assists techniques such as logistic regression to reduce bias in estimates, and assists effective learning for the more complicated techniques.

[insert Table 2 approximately here]

\subsection{Selection of Input Variables}

The input variables used are a key contributor to model performance, so the set of variables used in this study is more comprehensive than in any prior study in financial statement fraud detection. This increases the relevance of the findings from answering each research question. A large initial set of financial and non-financial variables was preferred while recognising the risk of multi-collinearity, because the issue is accounted for at the model building stage. Stepwise removal of variables is used with traditional regression models and variable selection is a feature of more complex models such as decision trees and ensembles of them.

This paper identified and selected input variables based on findings in prior studies that used US data and drawing justification from the Fraud Triangle theoretical framework. This approach answers the call by Dunstan and Gepp (2018) to develop big-data fraud models grounded in theory. There was also a preference for variables

This is the peer reviewed version of the following article: Gepp, A., Kumar, K., \& Bhattacharya, S. (2020). Lifting the Numbers Game: Identifying key input variables and a best-performing model to detect financial statement fraud. Accounting and Finance, which has been published in final form at https://doi.org/10.1111/acfi.12742. 
for which data are publicly available because variables for which data is too difficult to obtain are unlikely to be used in practice (Perols 2011). Moreover, quantitative approaches that use publicly available data can serve as benchmarks relative to which further refinements can be made if more restricted data from a very specific group of stakeholders became available (Feroz et al. 2000).

\subsubsection{The Initial Set of Input Variables}

Table 3 lists all 50 variables, including three new ones, by category; these are discussed below and shown in Figure 2. For each variable, Table 3 also lists the associated factor of the Fraud Triangle and the published research that provided empirical support for their use as an indicator of financial statement fraud.

Figure 2. Categories of input variables.

[insert Figure 2 approximately here]

Financial variables have been the most explored by far. They include specific accounts from financial statements including accounts receivable and its contra account (allowance for doubtful accounts), inventory and sales because these accounts are more likely to be fraudulently manipulated because of the increased fraud opportunity as a result of their being relatively difficult to audit (Fanning and Cogger 1998). Sales is also often a key performance indicator and so might gauge pressure on executives to fraudulently improve results. In addition to these specific accrual accounts and asset composition ratios derived from them, general accrual measures are also included because of the large body of literature that theorises earnings are primarily misstated by manipulating accruals (Dechow et al. 2011). General levels of debt and financial distress are also measured because they can increase pressure to fraudulently improve financials to avoid breaching debt covenants (Persons 1995). In contrast, increased scrutiny from debt holders could reduce fraud opportunities. Poor performance and profitability can also increase pressure to fraudulently improve financials (Perols and Lougee 2011), as can times of financing where an increased share price is particularly beneficial.

Non-financial variables describe characteristics of the external auditor, Chief Executive Officer (CEO), Chief Financial Officer (CFO) and board of directors, as well as changes over time. Substantial prior literature supports the inclusion of such variables including Carcello and Nagy (2004) finding more fraud in accounts with the same audit firm for three or fewer years. Finkelstein (1992) stated that longer serving CEOs have more power and influence. This power could result in less accountability to the board of directors and more opportunities to commit fraud; the same could also be true for CFOs. Researchers (Weisbach 1988; Beasley

This is the peer reviewed version of the following article: Gepp, A., Kumar, K., \& Bhattacharya, S. (2020). Lifting the Numbers Game: Identifying key input variables and a best-performing model to detect financial statement fraud. Accounting and Finance, which has been published in final form at https://doi.org/10.1111/acfi.12742. 
1996) have also shown that boards with more outsiders are more effective at monitoring management, which might reduce fraud opportunities.

Comparison variables measure whether financial growth rates are substantially higher than non-financial growth rates. Economics tells us that non-financial inputs into production such as the number of employees are correlated with the financial outputs from production such as the level of sales (Perols and Lougee 2011). However, because it is often difficult to fraudulently manipulate both categories simultaneously, discrepancies between the growth rates of these two categories can be considered suspicious and indicate fraud.

Control variables allow for differences in company size, age, industry and listing exchange. These features are already used in the matching process (see Section 2.1.1), but are still included because the matching is not exact and their inclusion allows for interactions with other variables in complex models such as tree-ensembles. Their inclusion is also consistent with prior studies (Perols and Lougee 2011; Erickson, Hanlon, and Maydew 2006) that included total assets as well as matching based on asset size.

Three new variables are also proposed. First, macroeconomic variables are included; changes in GDP, unemployment and retail sales allow for opportunities and pressures to vary based on economic conditions. Fraud examiners and academics have expressed opinions that fraud increases during economic recessions (e.g. ACFE 2009; Rezaee and Riley 2010). Poor economic conditions might increase the opportunity to commit fraud because control systems are weaker because of more emphasis on the downturn. Such conditions could also increase the pressure perceived by executives. Secondly, the G-index (Gompers, Ishii, and Metrick 2003) is used as a prominent corporate governance index that aggregates the existence of 24 governance provisions, because a lack of such governance can result in reduced monitoring of management that increase fraud opportunities. Past research has shown that weak corporate governance increases the likelihood of financial statement fraud (Hogan et al. 2008), and while a variety of individual corporate governance variables (such as the percentage of executives on the board) have been tested, there has been little empirical testing of corporate governance indices for use in fraud detection models. However, Kent, Stewart, and Christensen (2012) point out that there is support for both individual variables and indices for measuring corporate governance in the accounting literature. Thirdly, a measure of the accounting complexity of an industry is used because such complexity could create fraud opportunities as fewer people understand the rules. Quantifying the complexity of an industry is a difficult task. In contrast to using industry concentration measure as a proxy for complexity as

This is the peer reviewed version of the following article: Gepp, A., Kumar, K., \& Bhattacharya, S. (2020). Lifting the Numbers Game: Identifying key input variables and a best-performing model to detect financial statement fraud. Accounting and Finance, which has been published in final form at https://doi.org/10.1111/acfi.12742. 
done by Ndofor, Wesley, and Priem (2015), Seavey's (2011) measure has been chosen because it is calculated as the mean of ten different complexity measures.

\subsection{Framework for Comparative Analysis}

Models have been compared using a Weighted Error Cost (WEC) to allow like-with-like comparisons. The procedure to devise, apply and optimise this performance metric is outlined in the following subsections.

\subsubsection{Selection of the Ratios of Error Costs $\left(C_{I F}: C_{I L}\right)$}

As previously mentioned, because it depends on the particular conditions and stakeholders, it is best to consider a range of ratios. Consequently, we consider the largest range analysed in prior studies, which varied from 1:1 to 100:1 for the cost of missing fraud relative to falsely alleging fraud $\left(C_{I F}: C_{I L}\right)$. Most prior studies do not consider ratios greater than 50:1, and consequently no ratios in between 60:1 and 100:1 are considered, which is consistent with research conducted by Beneish (Beneish 1997, 1999a). Specifically, the ratios considered are 1:1, 10:1, 20:1, 30:1, 40:1, 50:1, 60:1 and 100:1.

\subsubsection{Determination of the Prior Probabilities of Fraud $[p(F)]$}

Recent research using classification models (Skousen and Wright 2008) has shown it is important to assess models using metrics that take the imbalanced data issue into account. Thus, the prior probability of fraud needs to be taken into account, but the exact value is unknown because frauds that have gone undetected remain unidentified. There is no standardized way of handling these varying estimates. For example, Perols (2011) handled the varying estimates of the proportion of statements that are fraudulent $[p(F)]$ by using values of $0.3 \%$, $0.6 \%$ and $1.2 \%$, while Bayley and Taylor (2007) considered values of $p(F)$ of $1 \%, 2 \%, 3 \%$ and $4 \%$. We extend this approach by including the substantially larger estimates by Dyck, Morse, and Zingales (2013) of 14.5\%, with a conservative lower bound of $5.5 \%$ (rounded to the nearest $0.5 \%$ ). These estimates have not been incorporated into previous financial statement fraud detection modelling studies. Specifically, the chosen values of $p(F)$ are: $0.4 \%$, as the lowest estimate with credible evidence (Dechow et al. 2011; Bernardi 1994); $1 \%$, as the most-used estimate in prior research (e.g. Feroz et al. 2000; Fanning and Cogger 1998; Lin, Hwang, and Becker 2003; McKee 2009); and 5.5\% and 14.5\% as the new largest estimates.

\subsubsection{Ratio of Error Costs Adjusted for Prior Probability of Fraud}

Instead of varying both the costs and priors $\left(C_{I F}: C_{I L}\right.$ and $\left.p(F)\right)$, Perols (2011) showed that one of them can be varied to represent changes. This reduction in parameters enables results to be presented in simpler graphs

This is the peer reviewed version of the following article: Gepp, A., Kumar, K., \& Bhattacharya, S. (2020). Lifting the Numbers Game: Identifying key input variables and a best-performing model to detect financial statement fraud. Accounting and Finance, which has been published in final form at https://doi.org/10.1111/acfi.12742. 
that facilitate improved interpretability. In contrast to Perols, this study manipulates only the relative cost of missing fraud to falsely alleging fraud (adjusted for prior probabilities) using the equation below, because costs are more easily interpreted than prior probabilities.

$$
\text { Prior - adjusted Relative Cost of Missing Fraud }\left(\operatorname{PaR}_{I F}\right)=\frac{C_{I F} \times p(F)}{C_{I L} \times p(L)}=\frac{C_{I F}}{C_{I L}} \times \frac{p(F)}{100 \%-p(F)} \text {. }
$$

As an example, a ratio of error costs of $40: 1$ indicates that missing a fraud is 40 times more costly than a false allegation of fraud. However, if only $5.5 \%$ of financial statements are fraudulent then missing fraud is $\frac{40}{1} \times \frac{5.5 \%}{100 \%-5.5 \%}=2$ times worse than falsely alleging fraud. Table 4 presents all 18 values that range from 0.004 to 17 , where larger numbers indicate higher costs of missing fraud (relative to falsely alleging fraud) or a larger prior probability of fraud, or both.

\section{[insert Table 4 approximately here]}

\subsubsection{Performance Metric: Weighted Error Cost (WEC)}

$\mathrm{PaRC}_{I F}$ is incorporated into the WEC by the following equation.

$$
W E C=\left\{\begin{array}{ll}
p_{I F} \times P a R C_{I F}+p_{I L} & \operatorname{PaRC}_{I F} \geq 1 \\
p_{I F}+p_{I L} \times \frac{1}{\operatorname{PaRC}_{I F}} & \operatorname{PaRC}_{I F}<1
\end{array} \quad\right. \text { where, }
$$

- $p_{I F}=$ the proportion (or percentage) of fraudulent statements incorrectly classified $=$ $\frac{\text { number of incorrectly classified fraudulent statements }}{\text { number of fraudulent statements }}$, and so $0 \leq p_{I F} \leq 1$;

- $p_{I L}=$ the proportion (or percentage) of legitimate statements incorrectly classified = $\frac{\text { number of incorrectly classified legitimate statements }}{\text { number of legitimate statements }}$, and so $0 \leq p_{I L} \leq 1$.

The definition of WEC is split as shown above so that the weight of the least costly error $\left(p_{I L}\right.$ when $\operatorname{PaRC}_{I F} \geq 1$ and $p_{I F}$ when $\left.\operatorname{PaRC}_{I F}<1\right)$ is one, which facilitates more intuitive assessment of performance. Consider a naïve model that classifies all financial statements as fraudulent when $\operatorname{PaRC}_{I F} \geq 1$ and legitimate when $P a R C_{I F}<1$. This naïve model will always have a WEC value of one, because

$$
\text { WEC }=\left\{\begin{array}{ll}
0 \% \times \operatorname{PaRC}_{I F}+100 \%=1 & \operatorname{PaRC}_{I F} \geq 1 \\
100 \%+0 \% \times \frac{1}{\text { PaRC IF }_{I F}=1} & \operatorname{PaRC}_{I F}<1
\end{array} .\right.
$$

Thus, WEC values less than one indicate performance better than the naïve model and WEC values greater than one indicate inferior performance.

This is the peer reviewed version of the following article: Gepp, A., Kumar, K., \& Bhattacharya, S. (2020). Lifting the Numbers Game: Identifying key input variables and a best-performing model to detect financial statement fraud. Accounting and Finance, which has been published in final form at https://doi.org/10.1111/acfi.12742. 


\subsubsection{Optimization of Cut-off Values}

Each model generates output values, commonly a probability of being fraudulent, that when compared to a cut-off value determine whether each financial statement is classified as legitimate or fraudulent. For example, values of less than 0.5 could be classified as legitimate, while values greater than or equal to 0.5 are classified as fraudulent. Instead of using a default cut-off value such as 0.5 , this current research uses the methodological improvement employed by Beneish (Beneish 1997, 1999a) that has also been used by a limited number of other researchers (Persons 1995; Bayley and Taylor 2007; Perols 2011). This improved methodology involves empirically determining the optimal cut-off values for each ratio of error costs $\left(C_{I F}: C_{I L}\right)$ and prior probability of fraud $[p(F)]$ as the value which minimizes the weighted error cost (WEC) on the training data set. As cutoff values are optimized based on the same training data used to develop models, the presence of any sample selection bias would be common to both processes and consequently not troublesome (Skogsvik 2005). The optimal cut-off value will then be used for making classifications on the holdout data set that has not been used during this optimization process.

To allow fair comparisons, cut-off values are optimized for all models, even those based on prior studies that did not perform the optimization. Robustness tests confirmed that optimizing the cut-off values did indeed improve results on the holdout sample.

\subsection{Model Building Techniques}

Table 5 represents the 32 different supervised learning models that have been chosen for comparison, after many more were initially analysed, in order to optimize the parameters for each model. The reasons for the choices are based on the literature review in Section 1.1 and are discussed in Appendix A. Models include regression-based discriminant analysis and logistic regression, artificial neural networks, support vector machines, decision trees and ensembles.

\section{[insert Table 5 approximately here]}

All models have been developed and tested on the same data so that comparisons between them were valid. Furthermore, all variable selections and parameter optimizations were conducted using only the training data (and cross-validated trials on the training data) to retain the testing set as a true holdout sample. Missing values were replaced based on the neutral value concept used by Beneish (1999a), which is preferable to removing statements that have missing values because that would greatly reduce the data size (Myrtveit, Stensrud, and Olsson 2001).

This is the peer reviewed version of the following article: Gepp, A., Kumar, K., \& Bhattacharya, S. (2020). Lifting the Numbers Game: Identifying key input variables and a best-performing model to detect financial statement fraud. Accounting and Finance, which has been published in final form at https://doi.org/10.1111/acfi.12742. 
The results are presented according to the research questions.

\section{1 $\quad$ Research Question 1 (RQ1)}

RQ1: What model is the best overall at detecting financial statement fraud, under varying assumptions about the prior probability of fraud and error cost ratios?

Overall, AV5_NoNN is the best model considering all investigated circumstances. Our AV5_NoNN model can be used off-the-shelf and offers a substantial improvement (as measured by lower WEC) over the existing benchmark models as shown in the first two columns of Table 6. This newly configured ensemble model averages the probability outputs of five other models, namely: a Random Forests, TreeNet (stochastic gradient boosting), CART decision tree, discriminant analysis and a logistic regression model.

[insert Table 6 approximately here]

\subsubsection{Selection of the Best Model Overall: AV5_NoNN}

The best non-ensemble models were clearly outperformed by ensemble models, but choosing between the ensemble models was not straightforward. Consequently, the performance of the best ensemble models was compared using a number of measures as described below and presented in Table 7. AV5_NoNN is clearly the best model overall. The three measures are:

- The number of values of $P a R C_{I F}$ for which the WEC is less than one, measuring how many times the model is superior to the naïve model classifying all statements the same way;

- The number of values of $P a R C_{I F}$ for which the WEC is the lowest model, measuring how many times the model is the best model; and,

- The average of the ranking (where lower WEC is preferred) for each value of $P a R C_{I F}$, measuring performance across all values of $P a R C_{I F}$.

The complete list of tabulated results for each model is available from the authors upon request.

[insert Table 7 approximately here]

\subsection{Research Question 2 (RQ2)}

RQ2: With regard to informed stakeholders who can estimate their specific error cost ratio and the prior probability of fraud, can they benefit from a tailored model instead of the best overall model from RQ1?

The cost of missing fraud relative to falsely alleging it differs depending on the circumstance and the stakeholder. When stakeholders can reasonably estimate their ratio of error costs and the prior probability of

This is the peer reviewed version of the following article: Gepp, A., Kumar, K., \& Bhattacharya, S. (2020). Lifting the Numbers Game: Identifying key input variables and a best-performing model to detect financial statement fraud. Accounting and Finance, which has been published in final form at https://doi.org/10.1111/acfi.12742. 
fraud, then a tailored model should be used according to Figure 3, because it results in $0-11 \%$ lower WEC as shown in the last column of Table 6 . For an investor, investing in a company with fraudulent financial statements has been estimated to be 20 to 30 times worse than the lost opportunity to invest in a company because it was falsely accused of being fraudulent (Beneish 1999a). Consider a hypothetical investor for whom the cost of missing fraud relative to falsely alleging fraud is $20: 1$ and who agrees with recent estimates that the prior probability of fraud is $14.5 \%$ (Dyck, Morse, and Zingales 2013). As indicated by the smaller table in Figure 3 , the corresponding value of $\operatorname{PaRC} C_{I F}$ is 3. Then, using the larger table in Figure 3, the best model would be RF_66, which is a Random Forests model that uses 1000 trees and all of the available variables. Such an investor using RF_66 reduces the WEC a further 5\% from the RQ1 model that was already 5\% better than the best benchmark.

Figure 3. An illustration of how to select the best model for a given circumstance and prior probability of fraud. [insert Figure 3 approximately here]

As the cost of missing fraud (relative to falsely alleging fraud) increases, the values of $\operatorname{PaRC}_{I F}$ increase. When this happens, Figure 3 shows that the percentage of fraud correctly detected increases at the expense of a decline in the percentage of legitimate statements that are correctly detected. At the extreme values of $P a R C_{I F}$, the best models are able to detect either fraud or legitimacy with perfect accuracy while still maintaining a small (non-zero) percentage accuracy of detecting the other. The overall percentage accuracy declines as the value of $\operatorname{PaRC}_{I F}$ moves further away from one, either above or below, which illustrates that fraud is easiest to detect when $\mathrm{PaRC}_{I F}$ is equal to one. This finding is true of all models in this research.

\subsubsection{Contributions to Literature about Modelling}

A CART decision tree was the most accurate non-ensemble modelling technique overall, followed by the best logistic regression (stepwise), which outperformed all the ANN and SVM models. This provides more clarity on the relative accuracy of logistic regression and ANNs, given the contrasting results in prior studies (Feroz et al. 2000; Perols 2011). For financial statement fraud detection, the superior results of logistic regression compared with ANNs have been substantiated in this study with increased reliability because of the relatively large holdout data set and set of input variables.

There have also been mixed results when comparing Random Forests (or bagging using decision trees) and logistic regression using cross-validation (Perols and Lougee 2011; Whiting et al. 2012). Additional clarity on the superior empirical performance of Random Forests is provided in this study by using a relatively large

This is the peer reviewed version of the following article: Gepp, A., Kumar, K., \& Bhattacharya, S. (2020). Lifting the Numbers Game: Identifying key input variables and a best-performing model to detect financial statement fraud. Accounting and Finance, which has been published in final form at https://doi.org/10.1111/acfi.12742. 
holdout sample, instead of previously used cross-validation. Table 7 shows that Random Forests (RF_66) has outperformed DT_One_DA in terms of WEC, which in turn outperformed the non-ensemble models including logistic regression.

Except for the lower values of $P a R C_{I F}$, ensemble models dominate the remaining circumstances. While their use in prior studies is limited, ensembles of decision trees (RF and TN models) were the best model on numerous occasions in this research. This is not surprising because both techniques have a random aspect that assists them to resist over-learning in the presence of imperfect data such as undetected fraud incorrectly labelled as legitimate in the training data. As indicated by the occurrence of model codes beginning with Vote or AV, ensembles of multiple modelling techniques (that include ensembles of decision trees) newly developed in the course of this research are also the best (or within $2 \%$ of the best) models on numerous occasions. This demonstrates that individual modelling techniques have different advantages, and performance gains are possible by using the increased information from combining them.

\subsection{Research Question 3 (RQ3)}

RQ3: Which explanatory variables are the most useful in models that detect financial statement fraud?

Although ensemble models were the most accurate, it is important to note that there is a trade-off because they are more complex and consequently more difficult to interpret than non-ensembles. Table 8 presents the stepwise logistic regression (LR_Step): model coefficients, their statistical significance and each variable's influence on the likelihood of fraud. This model was chosen because (i) logistic regression provides a simple interpretation of each variance's influence on the odds of fraud, (ii) LR_Step was the best model empirically that provides a test for statistical significance and (iii) the stepwise models are the least affected regression models by the problem of multicollinearity.

Confirming previous findings on a larger data set and larger set of input variables while controlling for multicollinearity with a stepwise logistic regression, the probability a financial statement is fraudulent is increased by:

- Higher levels of inventory relative to sales (V8), which is consistent with increased opportunity to fraudulently overvalue inventory by including obsolete inventory (Kaminski, Wetzel, and Guan 2004; Spathis 2002). Inventory is a target of fraudulent manipulation because of the increased opportunity as a result of its being difficult to audit (Fanning and Cogger 1998);

This is the peer reviewed version of the following article: Gepp, A., Kumar, K., \& Bhattacharya, S. (2020). Lifting the Numbers Game: Identifying key input variables and a best-performing model to detect financial statement fraud. Accounting and Finance, which has been published in final form at https://doi.org/10.1111/acfi.12742. 
- Lower levels of sales relative to total assets (V11). Lower ability to generate sales from assets can represent management who are less efficient (Fanning and Cogger 1998) and less able to cope with competitive situations (Persons 1995), which can increase the pressure to fraudulently improve performance;

- Smaller profits relative to equity (V27), which is consistent with increased pressure during times of poor profitability to fraudulently improve financial statements in order to hide the poor results (Perols and Lougee 2011);

- Larger profits relative to the average asset base in the prior two years (V28). In contrast to V27, the denominator of V28 measures prior years. These findings are consistent with lower current profitability (V27) reducing pressure to commit fraud, but higher profitability relative to past resources (V28) being suspicious and more likely to be a result of fraudulent manipulation of profits. Interestingly, both these accounting-based measures of performance were statistically significant, unlike the market-based performance measures involving holding period return (V29) and earnings per share (V30);

- New securities (common stock or long-term debt) being issued (V31) and likely to be needed to be issued in the near future (V33). This is consistent with management perceiving an increased pressure to fraudulently improve financials to improve the stock price during such times, because such an increase would directly reduce the cost of raising equity funds, and can result in more favourable contractual terms with debt funders;

- The use of operating leases (V34). Dechow et al. (2011) postulated that the use of operating leases could be associated with managers who are more focused on short-term window dressing, as the off balance sheet financing lowers initial expenses relative to capital leases. Such managers may then be more likely to be able to rationalise fraud to themselves by focusing on the short-term gain.

- A larger proportion of directors also being executives (V39). This is consistent with outsiders on boards (Beasley 1996) and directors who are not executives (Dechow, Sloan, and Sweeney 1996) playing an important monitoring role. A reduction in such monitoring creates more opportunities for management to commit and conceal financial statement fraud.

- Younger (V44) companies, which might be a result of increased financial pressure to commit fraud in younger firms around the period of the initial stock offering (Erickson, Hanlon, and Maydew 2006). Alternatively, young companies might not yet have the controls established to adhere to reporting requirements (Beasley 1996)

- Larger (V45) companies. Although this finding seems to contradict the thought that smaller firms have weaker internal controls, it could simply indicate that the US SEC has a bias to prosecute larger firms (see Section 2.1) and consequently is not listed in Table 9 as a key variable finding.

- Firms with Standard Industrial Classification (SIC) codes not starting with a 3 (V46), which are primarily not computer companies. This is the opposite finding of previous research, and indicates this result might 
be purely an empirical result specific to the time period being studied, and so is not listed in Table 9 as a key variable finding.

There were also novel findings relating to variables. Contrary to prior research findings, more debt (relative to equity V24) was associated with fewer frauds. This is likely the result of a decrease in the opportunity to commit fraud because of increased monitoring and scrutiny from creditors, which is consistent with Jensen and Meckling's (1976) well-established agency theory. This new empirical finding might have been revealed as a consequence of using a more comprehensive set of input variables data with a relatively large number of fraud cases.

While mixed results have occurred in prior studies, measures of total accruals (V19 and V20) were noticeably more important than a measure of discretionary (V21) or unadjusted accruals (V22). Positive (V20) and relatively large (V19) total accruals were associated with increased levels of fraud, consistent with the literature that theorises earnings are primarily misstated by manipulating accruals (Dechow et al. 2011). Prior positive accruals (V20) also reduce ways to legitimately manage earnings and so may increase the pressure to commit fraud if management attempts to avoid accrual reversals or maintain accrual growth as a means to improve earnings (Beneish 1997; Perols and Lougee 2011).

Considering the newly proposed variables, although not contained in stepwise logistic regression, the Gindex (V49) was statistically significant at a $10 \%$ level in the logistic regression model with all variables (LR_All). More importantly, it was also significant at a $1 \%$ level in the stepwise discriminant analysis (DA_Step) that possessed comparable accuracy with stepwise logistic regression. These results indicate more fraud is associated with more provisions that restrict shareholder rights. This is the first study to empirically support the hypothesis that financial statement fraud is related to the aggregation of many corporate governance initiatives (as measured by an index), not just the presence or absence of a particular one. However, no substantial support was found for macroeconomic variables (V48) or the accounting complexity measure (V50) across all the parametric and non-parametric models in this research.

\section{$4 \quad$ Conclusion and Future Research Directions}

This research enables practitioners and researchers to make an informed choice when selecting a financial fraud detection model rather than falling back to popular, yet dated, models. Many had a substantially lower error (WEC) than the benchmark F-score and M-score models. The best overall is the ensemble AV5_NoNN, which outperforms both benchmark models and all others tested. AV5_NoNN was newly configured as part of

This is the peer reviewed version of the following article: Gepp, A., Kumar, K., \& Bhattacharya, S. (2020). Lifting the Numbers Game: Identifying key input variables and a best-performing model to detect financial statement fraud. Accounting and Finance, which has been published in final form at https://doi.org/10.1111/acfi.12742. 
this research and is the best default choice. However, for informed stakeholders who can reliably estimate their ratio of errors costs and the prior probability of fraud, further improvements can be made by choosing the best model under those conditions (See Figure 3). The fact that no model is superior in all scenarios illustrates the importance for future research to consider a variety of scenarios as has been done in this study by using our devised cost-based metric (WEC) to evaluate model performance.

Both financial and non-financial variables were found to be statistically significant; key findings are summarised in Table 9. New results have been found, as well as confirming prior results on a larger data set with more variables while handling multicollinearity concerns with stepwise techniques. More debt relative to equity reduces financial statement fraud risk, consistent with agency theory in terms of increase monitoring by debtholders, but contrary to prior empirical findings using smaller data sets. Positive and relatively large total accruals increase fraud risk; total accruals are more important than discretionary or unadjusted accruals, providing clarity to mixed results in prior research. The corporate governance G-index has not previously been evaluated for detecting financial statement fraud; in this study we found more corporate governance (as indicated by larger G-index values) in aggregate reduce the opportunity to commit fraud. Overall, support was found for variables measuring all factors of the Fraud Triangle, but additional research into variables that measure the rationalisation factor would be beneficial as less focus has been placed on them in prior research. It would also be worth investigating enhancing models in this research with findings from gender-based fraud research (Capezio and Mavisakalyan 2016) and text-mining research (e.g. Purda and Skillicorn 2015).

The findings are strengthened by using the most comprehensive set of input variables and modelling techniques to date. The number of fraud cases used in this research is substantially greater than in most prior studies, and the sample size is in fact more than double relative to sample sizes used in some of the prior studies. This work is arguably the first study of its kind to evaluate models using holdout data for accurate performance assessment and to do so over a range of stakeholder-specific errors cost ratios and assumptions about the prior probability of fraud. Further, models are evaluated on holdout data that occur chronologically after the training data used to develop them, which results in more realistic estimates of model performance. In total, 32 different models have been compared on the same data to allow valid comparisons. Some models are based on those used in prior studies, whereas others are modifications of previously used models, and entirely new ones have also been developed. Robustness tests confirmed that optimising cut-off values improved performance for both existing and new models. The comparisons between models is an important contribution because this was not

This is the peer reviewed version of the following article: Gepp, A., Kumar, K., \& Bhattacharya, S. (2020). Lifting the Numbers Game: Identifying key input variables and a best-performing model to detect financial statement fraud. Accounting and Finance, which has been published in final form at https://doi.org/10.1111/acfi.12742. 
previously possible as results in prior studies are presented in a way that does not permit comparison between all of them.

Although the models presented are limited to the US, the methodology used can easily be adapted to other countries. The ACFE (2018) found few differences across the globe, and so models developed in this study may be able to be used in many countries without adaptation. There is a precedent for this in the field of business failure prediction where Altman's Z-score model (Altman 1968) estimated on US data has been widely used in many other countries. Research into country-specific improvements would also be valuable, such as a model for China that includes measures of corporate social responsibility (Liao, Chen, and Zheng 2019) and the political backgrounds of directors (Kong et al. 2019).

Financial statement fraud continues to be extremely costly to society, but this research can be used to improve its early detection, which would mitigate its social cost and help deter it. There are also specific beneficiaries of this information such as auditors, directors and regulators, who can use detection models to assist them to better assess the risk of fraud having occurred and decide whether experts need investigate further. That is, fraud detection models are to complement, not replace, human specialists. Additionally, investors, financiers and employees are examples of stakeholders who can use detection models to help them avoid prolonged association with fraudulent companies.

It is important to note that even the most complex ensemble models developed in this research can be efficiently automated to make them usable by all stakeholders; and therefore have a strong industry uptake potential. There is also an opportunity from this study to investigate the effects on portfolio performance of using the best overall fraud detection model AV5_NoNN to guide an investment strategy.

This is the peer reviewed version of the following article: Gepp, A., Kumar, K., \& Bhattacharya, S. (2020). Lifting the Numbers Game: Identifying key input variables and a best-performing model to detect financial statement fraud. Accounting and Finance, which has been published in final form at https://doi.org/10.1111/acfi.12742. 


\section{References}

Abbott, L. J., S. Parker, and G. F. Peters, 2004, Audit Committee Characteristics and Restatements, AUDITING: A Journal of Practice \& Theory 23, 69-87.

ACFE, 2009, Occupational Fraud: A Study of the Impact of an Economic Recession (Association of Certified Fraud Examiners, www.acfe.com).

- 2018, Report to the Nations on Occupational Fraud and Abuse (Association of Certified Fraud Examiners, www.acfe.com).

Alden, M. E., D. M. Bryan, B. J. Lessley, and A. Tripathy, 2012, Detection of Financial Statement Fraud Using Evolutionary Algorithms, Journal of Emerging Technologies in Accounting 9, 7194.

Altman, E. I., 1968, Financial Ratios, Discriminant Analysis and the Prediction of Corporate Bankruptcy, Journal of Finance 23, 589-609.

Bai, B., J. Yen, and X. Yang, 2008, False financial statements: characteristics of China's listed companies and CART detecting approach, International Journal of Information Technology \& Decision Making 07, 339-359.

Bayley, L., and S. L. Taylor, 2007, Identifying Earnings Overstatements: A Practical Test available at SSRN: http://ssrn.com/abstract=995957).

Beasley, M. S., 1996, An empirical analysis of the relation between the board of director composition and financial statement fraud, The Accounting Review 71, 443-465.

Beasley, M. S., J. V. Carcello, D. R. Hermanson, and T. L. Neal, 2010, Fraudulent Financial Reporting: 1998 - 2007. An Analysis of U.S. Public Companies. (The Committee of Sponsoring Organizations of the Treadway Commission (COSO), www.coso.org).

Bell, T. B., and J. V. Carcello, 2000, A decision aid for assessing the likelihood of fraudulent financial reporting, AUDITING: A Journal of Practice \& Theory 19, 169-184.

Beneish, M. D., 1997, Detecting GAAP violation: implications for assessing earnings management among firms with extreme financial performance, Journal of Accounting and Public Policy 16, 271-309.

, 1999a, The detection of earnings manipulation, Financial Analysts Journal 55, 24-36.

, 1999b, Incentives and penalties related to earnings overstatements that violate GAAP, The Accounting Review 74, 425-457.

Bernardi, R. A., 1994, Fraud detection: The effect of client integrity and competence and auditor cognitive style, AUDITING: A Journal of Practice \& Theory 13, 68-84.

Bhattacharya, S., D. Xu, and K. Kumar, 2011, An ANN-based auditor decision support system using Benford's law, Decision Support Systems 50, 576-584.

Brazel, J. F., K. L. Jones, and M. F. Zimbelman, 2009, Using Nonfinancial Measures to Assess Fraud Risk, Journal of Accounting Research 47, 1135-1166.

Breiman, L., J. H. Friedman, R. Olshen, and C. J. Stone, 1984, Classification and Regression Trees (Wadsworth \& Brooks.

Busta, B., and R. Weinberg, 1998, Using Benford's law and neural networks as a review procedure, Managerial Auditing Journal 13, 356-366.

Capezio, A., and A. Mavisakalyan, 2016, Women in the boardroom and fraud: Evidence from Australia, Australian Journal of Management 41, 719-734.

Carcello, J. V., and A. L. Nagy, 2004, Audit Firm Tenure and Fraudulent Financial Reporting, AUDITING: A Journal of Practice \& Theory 23, 55-69.

Cressey, D., 1953, Other people's money: a study in the social psychology of embezzlement (Free Press, Glencoe, Illinois, USA).

Dechow, P., R. Sloan, and A. Sweeney, 1996, Causes and consequences of earnings manipulations: An analysis of firms subject to enforcement actions by the SEC, Contemporary Accounting Research 13, 1-36.

Dechow, P. M., W. Ge, C. R. Larson, and R. G. Sloan, 2011, Predicting Material Accounting Misstatements, Contemporary Accounting Research 28, 17-82.

This is the peer reviewed version of the following article: Gepp, A., Kumar, K., \& Bhattacharya, S. (2020). Lifting the Numbers Game: Identifying key input variables and a best-performing model to detect financial statement fraud. Accounting and Finance, which has been published in final form at https://doi.org/10.1111/acfi.12742. 
Dechow, P. M., W. Ge, and C. Schrand, 2010, Understanding earnings quality: A review of the proxies, their determinants and their consequences, Journal of Accounting and Economics 50, 344-401.

Desai, H., C. E. Hogan, and M. S. Wilkins, 2006, The Reputational Penalty for Aggressive Accounting: Earnings Restatements and Management Turnover, The Accounting Review 81, 83-112.

Dorminey, J., A. S. Fleming, M.-J. Kranacher, and R. A. Riley, Jr., 2012, The Evolution of Fraud Theory, Issues in Accounting Education 27, 555-579.

Dunstan, K., and A. Gepp, 2018, Guest editorial, Pacific Accounting Review 30, 130-134.

Dyck, A., A. Morse, and L. Zingales, 2013, How Pervasive is Corporate Fraud? (Rotman School of Management Working Paper No. 2222608, available at SSRN: http://ssrn.com/abstract=2222608).

Erickson, M., M. Hanlon, and E. L. Maydew, 2006, Is There a Link between Executive Equity Incentives and Accounting Fraud?, Journal of Accounting Research 44, 113-143.

Fanning, K. M., and K. O. Cogger, 1998, Neural Network Detection of Management Fraud Using Published Financial Data, International Journal of Intelligent Systems in Accounting Finance \& Management 7, 21-41.

Feroz, E. H., T. M. Kwon, V. S. Pastena, and K. Park, 2000, The efficacy of red flags in predicting the SEC's targets: an artificial neural networks approach, Intelligent Systems in Accounting, Finance \& Management 9, 145-157.

Finkelstein, S., 1992, Power in Top Management Teams: Dimensions, Measurement, and Validation, The Academy of Management Journal 35, 505-538.

Free, C., 2015, Looking through the fraud triangle: a review and call for new directions, Meditari Accountancy Research 23, 175-196.

Gepp, A., 2015, Financial Statement Fraud Detection Using Supervised Learning Methods, Ph.D. Thesis (Bond University.

Gepp, A., K. Kumar, and S. Bhattacharya, 2010, Business failure prediction using decision trees, Journal of Forecasting 29, 536-555.

Gepp, A., M. K. Linnenluecke, T. J. O’Neill, and T. Smith, 2018, Big data techniques in auditing research and practice: Current trends and future opportunities, Journal of Accounting Literature 40, 102-115.

Gompers, P., J. Ishii, and A. Metrick, 2003, Corporate Governance and Equity Prices, The Quarterly Journal of Economics 118, 107-155.

Green, B. P., and J. H. Choi, 1997, Assessing the risk of management fraud through neural network technology, AUDITING: A Journal of Practice \& Theory 16, 14-28.

Hand, D., 2009a, Mismatched models, wrong results, and dreadful decisions: on choosing appropriate data mining tools, Paper presented at the 15th ACM SIGKDD International Conference on Knowledge Discovery and Data Mining, Paris.

Hand, D. J., 2009b, Measuring classifier performance: a coherent alternative to the area under the ROC curve, Machine Learning 77, 103-123.

Hogan, C. E., Z. Rezaee, R. A. Riley, and U. K. Velury, 2008, Financial Statement Fraud: Insights from the Academic Literature, AUDITING: A Journal of Practice \& Theory 27, 231-252.

Hoogs, B., T. Kiehl, C. Lacomb, and D. Senturk, 2007, A genetic algorithm approach to detecting temporal patterns indicative of financial statement fraud, Intelligent Systems in Accounting, Finance \& Management 15, 41-56.

Humpherys, S. L., K. C. Moffitt, M. B. Burns, J. K. Burgoon, and W. F. Felix, 2011, Identification of fraudulent financial statements using linguistic credibility analysis, Decision Support Systems 50, 585-594.

Jensen, M. C., and W. H. Meckling, 1976, Theory of the firm: Managerial behavior, agency costs and ownership structure, Journal of Financial Economics 3, 305-360.

Johnson, S. A., H. E. Ryan, and Y. S. Tian, 2009, Managerial Incentives and Corporate Fraud: The Sources of Incentives Matter, Review of Finance 13, 115-145.

Kaminski, K., T. S. Wetzel, and L. Guan, 2004, Can financial ratios detect fraudulent financial reporting?, Managerial Auditing Journal 19, 15-28.

This is the peer reviewed version of the following article: Gepp, A., Kumar, K., \& Bhattacharya, S. (2020). Lifting the Numbers Game: Identifying key input variables and a best-performing model to detect financial statement fraud. Accounting and Finance, which has been published in final form at https://doi.org/10.1111/acfi.12742. 
Karpoff, J. M., A. Koester, D. S. Lee, and G. S. Martin, 2017, Proxies and databases in financial misconduct research, The Accounting Review 92, 129-163.

Kedia, S., and T. Philippon, 2009, The Economics of Fraudulent Accounting, The Review of Financial Studies 22, 2169-2199.

Kent, P., J. Stewart, and J. Christensen, 2012, Alternative Markets for Non-audit Services in a Voluntary Setting, Paper presented at the 24th Asia-Pacific Conference on International Accounting Issues, Maui, Hawaii.

Kiehl, T., B. Hoogs, C. LaComb, and D. Senturk, 2005, Evolving Multi-Variate Time-Series Patterns for the Discrimination of Fraudulent Financial Filings, Paper presented at the Genetic and Evolutionary Computation Conference (GECCO), Wahington, DC, USA.

Kong, D., J. Xiang, J. Zhang, and Y. Lu, 2019, Politically connected independent directors and corporate fraud in China, Accounting \& Finance 58, 1347-1383.

Kotsiantis, S., E. Koumanakos, D. Tzelepis, and V. Tampakas, 2007, Forecasting fraudulent financial statements using data mining, International Journal of Computational Intelligence 3, 104-110.

KPMG Forensic, 2012, A survey of fraud, bribery and corruption in Australia \& New Zealand 2012 retrieved from http://www.kpmg.com/au/en/issuesandinsights/articlespublications/fraudsurvey/pages/default.aspx).

Lee, T. A., R. W. Ingram, and T. P. Howard, 1999, The difference between earnings and operating cash flow as an indicator of financial reporting fraud, Contemporary Accounting Research 16, 749-786.

Liao, L., G. Chen, and D. Zheng, 2019, Corporate social responsibility and financial fraud: evidence from China, Accounting \& Finance 59, 3133-3169.

Lin, J., M. Hwang, and J. Becker, 2003, A fuzzy neural network for assessing the risk of fraudulent financial reporting, Managerial Auditing Journal 18, 657-665.

McKee, T. E., 2009, A Meta-Learning Approach to Predicting Financial Statement Fraud, Journal of Emerging Technologies in Accounting 6, 5-26.

Morales, J., Y. Gendron, and H. Guénin-Paracini, 2014, The construction of the risky individual and vigilant organization: A genealogy of the fraud triangle, Accounting, Organizations and Society 39, 170-194.

Myrtveit, I., E. Stensrud, and U. H. Olsson, 2001, Analyzing data sets with missing data: an empirical evaluation of imputation methods and likelihood-based methods, IEEE Transactions on Software Engineering 27, 999-1013.

Nagadevara, V., 2010, Hybrid models and error weighting for predicting customer churn in telecom industry, Review of Business Research 10, 83-87.

Ndofor, H. A., C. Wesley, and R. L. Priem, 2015, Providing CEOs With Opportunities to Cheat: The Effects of Complexity-Based Information Asymmetries on Financial Reporting Fraud, Journal of Management 41, 1774-1797.

Ngai, E. W. T., Y. Hu, Y. H. Wong, Y. Chen, and X. Sun, 2011, The application of data mining techniques in financial fraud detection: A classification framework and an academic review of literature, Decision Support Systems 50, 559-569.

Partnoy, F., 2010, Infectious Greed : How Deceit and Risk Corrupted the Financial Markets (Profile Books, London).

Perols, J., 2011, Financial Statement Fraud Detection: An Analysis of Statistical and Machine Learning Algorithms, AUDITING: A Journal of Practice \& Theory 30, 19-50.

Perols, J. L., and B. A. Lougee, 2011, The relation between earnings management and financial statement fraud, Advances in Accounting 27, 39-53.

Persons, O. S., 1995, Using financial statement data to identify factors associated with fraudulent financial reporting, Journal of Applied Business Research 11, 38-46.

Phua, C., V. Lee, K. Smith, and R. Gayler, 2010, A Comprehensive Survey of Data Mining-based Fraud Detection Research (Computing Research Repository (CoRR), available at http://arxiv.org/abs/1009.6119).

Platt, J., 1999, Probabilistic outputs for support vector machines and comparisons to regularized likelihood methods, Advances in large margin classifiers 10, 61-74.

This is the peer reviewed version of the following article: Gepp, A., Kumar, K., \& Bhattacharya, S. (2020). Lifting the Numbers Game: Identifying key input variables and a best-performing model to detect financial statement fraud. Accounting and Finance, which has been published in final form at https://doi.org/10.1111/acfi.12742. 
Purda, L., and D. Skillicorn, 2015, Accounting variables, deception, and a bag of words: assessing the tools of fraud detection, Contemporary Accounting Research 32, 1193-1223.

Rezaee, Z., and R. Riley, 2010, Financial statement fraud: prevention and detection (Wiley, Hoboken, N.J).

Richardson, S. A., R. G. Sloan, M. T. Soliman, and İ. Tuna, 2005, Accrual reliability, earnings persistence and stock prices, Journal of Accounting and Economics 39, 437-485.

Seavey, S. E., 2011, Industry Complexity and the Importance of Industry Leadership Versus Engagement Office Size on the Quality of Audit Outcomes, Ph.D. Thesis (University of Missouri.

SEC, Listing and Delisting Requirements http://www.sec.gov/answers/listing.htm) cited September 2014], available from http://www.sec.gov/answers/listing.htm

Skogsvik, K., 2005, On the Choice-Based Sample Bias in Probabilistic Business Failure Prediction, SSE/EFI Working Paper Series in Business Administration, Retrieved from http://EconPapers.repec.org/RePEc:hhb:hastba:2005 2013.

Skousen, C., K. Smith, and C. Wright, 2009, Detecting and predicting financial statement fraud: The effectiveness of the fraud triangle and SAS No. 99, Advances in Financial Economics 13 (Corporate Governance and Firm Performance), 53-81.

Skousen, C., and C. Wright, 2008, Contemporaneous risk factors and the prediction of financial statement fraud, Journal of Forensic Accounting IX, 37-62.

Spathis, C., 2002, Detecting false financial statements using published data: some evidence from Greece, Managerial Auditing Journal 17, 179-191.

Summers, S. L., and J. T. Sweeney, 1998, Fraudulently Misstated Financial Statements and Insider Trading: An Empirical Analysis, The Accounting Review 73, 131-146.

Sutton, C. D., 2005, Classification and Regression Trees, Bagging, and Boosting, in E. J. W. C.R. Rao and J. L. Solka eds, Handbook of Statistics (Elsevier, 303-329.

Tan, D. T., L. Chapple, and K. D. Walsh, 2015, Corporate fraud culture: Re-examining the corporate governance and performance relation, Accounting \& Finance 57, 597-620.

Veganzones, D., and E. Séverin, 2018, An investigation of bankruptcy prediction in imbalanced datasets, Decision Support Systems 112, 111-124.

Weisbach, M. S., 1988, Outside Directors and CEO Turnover, Journal of Financial Economics 20, 431-460.

Whiting, D. G., J. V. Hansen, J. B. McDonald, C. Albrecht, and W. S. Albrecht, 2012, Machine Learning Methods For Detecting Patterns Of Management Fraud, Computational Intelligence 28, 505-527.

This is the peer reviewed version of the following article: Gepp, A., Kumar, K., \& Bhattacharya, S. (2020). Lifting the Numbers Game: Identifying key input variables and a best-performing model to detect financial statement fraud. Accounting and Finance, which has been published in final form at https://doi.org/10.1111/acfi.12742. 
Table 1. Summary of most relevant studies. Further information about model accuracy is not included because the studies have not presented it in a way that permits comparison between all of them. This lack of comparability is addressed in this paper by conducting a large comparative study.

\begin{tabular}{|c|c|c|c|}
\hline Study & Modelling Technique & Test Data & Consideration of Costs \\
\hline (Persons 1995) & Logistic Regression & $\begin{array}{c}\text { Jackknife } \\
\text { Cross-validation }\end{array}$ & $\begin{array}{l}\text { Cost ratios 1-30:1, } \\
\text { optimized cut-off values }\end{array}$ \\
\hline $\begin{array}{c}\text { (Green and Choi } \\
\text { 1997) }\end{array}$ & Backpropagation Neural Network & Random Holdout & No, 0.5 cut-off \\
\hline $\begin{array}{l}\text { M-score (Beneish } \\
\text { 1997, 1999a) }\end{array}$ & Probit Analysis & $\begin{array}{c}\text { Holdout } \\
\text { chronologically } \\
\text { after training }\end{array}$ & $\begin{array}{l}\text { Cost ratios 1-100:1, } \\
\text { optimized cut-off values }\end{array}$ \\
\hline $\begin{array}{l}\text { (Fanning and } \\
\text { Cogger 1998) }\end{array}$ & $\begin{array}{l}\text { Neural Network optimized by } \\
\text { Evolutionary Algorithm (best), } \\
\text { Logistic Regression, } \\
\text { Discriminant Analysis }\end{array}$ & $\begin{array}{l}\text { Holdout } \\
\text { chronologically } \\
\text { after training }\end{array}$ & $\begin{array}{l}\text { No, } \\
\text { assumed equal }\end{array}$ \\
\hline $\begin{array}{l}\text { (Summers and } \\
\text { Sweeney 1998) }\end{array}$ & Multi-stage Logistic Regression & No & No, 0.5 cut-off used \\
\hline $\begin{array}{l}\text { (Lee, Ingram, and } \\
\text { Howard 1999) }\end{array}$ & Logistic Regression & No & Cut-offs $0.1,0.2,0.3$ \\
\hline $\begin{array}{l}\text { (Bell and Carcello } \\
\text { 2000) }\end{array}$ & Logistic Regression & Random Holdout & $\begin{array}{l}\text { Cut-offs } 0.05-0.95 \\
\text { in } 0.05 \text { intervals }\end{array}$ \\
\hline (Feroz et al. 2000) & $\begin{array}{c}\text { Logistic Regression, } \\
\text { Neural Network (comparable) }\end{array}$ & Random Holdout & $\begin{array}{c}\text { Cost ratios } \\
1-40: 1 \\
\end{array}$ \\
\hline $\begin{array}{l}\text { (Lin, Hwang, and } \\
\text { Becker 2003) }\end{array}$ & $\begin{array}{c}\text { Backpropagation Neural } \\
\text { Network using Fuzzy Logic (best } \\
\text { for cost ratios }>30: 1 \text { ), } \\
\text { Logistic Regression }\end{array}$ & Unspecified Holdout & $\begin{array}{l}\text { Cost ratios } \\
1-100: 1\end{array}$ \\
\hline $\begin{array}{c}\text { (Kaminski, } \\
\text { Wetzel, and Guan } \\
\text { 2004) }\end{array}$ & Discriminant Analysis & $\begin{array}{c}\text { Jackknife } \\
\text { Cross-validation }\end{array}$ & No \\
\hline $\begin{array}{l}\text { (Kiehl et al. 2005; } \\
\text { Hoogs et al. 2007) }\end{array}$ & $\begin{array}{c}\text { Logistic Regression, } \\
\text { Genetic Algorithm (comparable) }\end{array}$ & Random Holdout & No \\
\hline $\begin{array}{l}\text { (Bayley and } \\
\text { Taylor 2007) }\end{array}$ & Logistic Regression & No & $\begin{array}{l}\text { Cost ratios 20-50:1, } \\
\text { optimized cut-off values }\end{array}$ \\
\hline $\begin{array}{l}\text { (Skousen and } \\
\text { Wright 2008; } \\
\text { Skousen, Smith, } \\
\text { and Wright 2009) }\end{array}$ & Discriminant Analysis & $\begin{array}{c}\text { Jackknife } \\
\text { Cross-validation }\end{array}$ & No \\
\hline (McKee 2009) & $\begin{array}{c}\text { Backpropagation Neural Network, } \\
\text { Logistic Regression, } \\
\text { See5 Decision Tree, } \\
\text { Ensemble of the above (best) }\end{array}$ & Inconsistent & $\begin{array}{l}\text { Cost ratios } \\
1-50: 1\end{array}$ \\
\hline $\begin{array}{l}\text { F-score (Dechow } \\
\text { et al. 2011) }\end{array}$ & Logistic Regression & $\begin{array}{l}\text { Holdout } \\
\text { chronologically } \\
\text { after training }\end{array}$ & $\begin{array}{l}\text { Varied F-score cut-off to } \\
\text { model different cost ratios }\end{array}$ \\
\hline (Perols 2011) & $\begin{array}{c}\text { Logistic Regression (best), } \\
\text { Support Vector Machine (best), } \\
\text { Artificial Neural Network, } \\
\text { See4.5 Decision Trees, } \\
\text { Bagging using See4.5, } \\
\text { Ensemble of the above }\end{array}$ & $\begin{array}{l}\text { Ten-fold } \\
\text { Cross-validation }\end{array}$ & $\begin{array}{l}\text { Considered in both model } \\
\text { building and evaluation, } \\
\text { Cost ratios 1-100:1, } \\
\text { Optimized cut-off values }\end{array}$ \\
\hline $\begin{array}{l}\text { (Alden et al. } \\
\text { 2012) }\end{array}$ & $\begin{array}{c}\text { Genetic and Markovian Learning } \\
\text { Algorithm (comparable), } \\
\text { both with Fuzzy Logic }\end{array}$ & $\begin{array}{c}\text { Ten-fold } \\
\text { Cross-validation }\end{array}$ & No \\
\hline
\end{tabular}

This is the peer reviewed version of the following article: Gepp, A., Kumar, K., \& Bhattacharya, S. (2020). Lifting the Numbers Game: Identifying key input variables and a best-performing model to detect financial statement fraud. Accounting and Finance, which has been published in final form at https://doi.org/10.1111/acfi.12742. 


\begin{tabular}{|c|c|c|c|}
\hline Study & Modelling Technique & Test Data & Consideration of Costs \\
\hline $\begin{array}{c}\text { (Whiting et al. } \\
2012)\end{array}$ & $\begin{array}{c}\text { Probit Analysis, Rule Ensemble, } \\
\text { Logistic Regression, } \\
\text { Partially Adaptive Estimators, } \\
\text { Stochastic Gradient Boosting, } \\
\text { Random Forests (best) }\end{array}$ & $\begin{array}{c}\text { Ten-fold } \\
\text { Cross-validation }\end{array}$ & $\begin{array}{c}\text { Performance measured } \\
\text { by area under the } \\
\text { ROC curve }\end{array}$ \\
\hline $\begin{array}{c}\text { (Purda and } \\
\text { Skillicorn 2015) }\end{array}$ & $\begin{array}{c}\text { Text analysis approach using } \\
\text { Bag-of-Words, Random Forest } \\
\text { and a Support Vector Machine }\end{array}$ & $\begin{array}{c}\text { Holdout } \\
\text { (Assumed Random) }\end{array}$ & $\begin{array}{c}\text { Performance measured } \\
\text { by area under the } \\
\text { ROC curve }\end{array}$ \\
\hline
\end{tabular}

This is the peer reviewed version of the following article: Gepp, A., Kumar, K., \& Bhattacharya, S. (2020). Lifting the Numbers Game: Identifying key input variables and a best-performing model to detect financial statement fraud. Accounting and Finance, which has been published in final form at https://doi.org/10.1111/acfi.12742. 
Table 2. The final data set used in this research.

\begin{tabular}{|l|c|c|c|}
\hline \multirow{2}{*}{ Data set } & \multicolumn{3}{|c|}{ Number of Financial Statements } \\
\cline { 2 - 4 } & Fraudulent & Legitimate & Total \\
\hline Training $(\leq 2002)$ & 295 & 295 & $590(63.6 \%)$ \\
\hline Holdout for Testing $(\geq 2003)$ & 169 & 169 & $338(36.4 \%)$ \\
\hline All & 464 & 464 & $928(100 \%)$ \\
\hline
\end{tabular}

This is the peer reviewed version of the following article: Gepp, A., Kumar, K., \& Bhattacharya, S. (2020). Lifting the Numbers Game: Identifying key input variables and a best-performing model to detect financial statement fraud. Accounting and Finance, which has been published in final form at https://doi.org/10.1111/acfi.12742. 
Table 3. List of variables used in this research, along with the associated factor(s) of the Fraud Triangle (FT) framework (according to the rationale provided in the prior study or studies suggesting their use). It should be noted that some variables have been calculated in a number of ways in the literature. For example, the first variable has been used as the value in the current year, the one-year percentage change and a binary variable indicating whether that percentage change is greater than $10 \%$. In such cases, all substantially different calculations have been used. Exact variable definitions are provided by Gepp (2015).

* indicates variables that were excluded from empirical analysis because of more than $80 \%$ missing data.

\begin{tabular}{|c|c|c|}
\hline ID & Variable (study(-ies) that provide empirical findings to substantiate their inclusion) & FT Factor(s) \\
\hline \multicolumn{3}{|c|}{ Financial Variables: Accounts Receivable, Allowance for Doubtful Accounts (AFDA), Inventory and Sales } \\
\hline V1 & $\begin{array}{l}\text { Accounts Receivable (and changes in it) (Perols 2011; Green and Choi 1997; Lin, } \\
\text { Hwang, and Becker 2003; Fanning and Cogger 1998; Perols and Lougee 2011) }\end{array}$ & $\mathrm{O}$ \\
\hline V2 & $\begin{array}{l}\text { Change in Accounts Receivable to Sales (Beneish 1997; Green and Choi 1997; } \\
\text { Beneish 1999a; Feroz et al. 2000; Lin, Hwang, and Becker 2003; Alden et al. 2012) }\end{array}$ & $\mathrm{O}$ \\
\hline V3 & $\begin{array}{l}\text { Change in Accounts Receivable to Total Assets } \\
\text { (Green and Choi 1997; Lin, Hwang, and Becker 2003; Dechow et al. 2011) }\end{array}$ & $\mathrm{O}$ \\
\hline V4 & $\begin{array}{l}\text { Change in Allowance for Doubtful Debt (AFDA) } \\
\text { (Green and Choi 1997; Lin, Hwang, and Becker 2003) }\end{array}$ & $\mathrm{O}$ \\
\hline V5 & $\begin{array}{l}\text { Change in AFDA to Accounts Receivable (Green and Choi 1997; Lin, Hwang, and } \\
\text { Becker 2003) }\end{array}$ & $\mathrm{O}$ \\
\hline V6 & Change in AFDA to Sales (Green and Choi 1997; Lin, Hwang, and Becker 2003) & $\mathrm{O}$ \\
\hline V7 & Change in Inventory to average Total Assets (Dechow et al. 2011) & $\mathrm{O}$ \\
\hline V8 & $\begin{array}{l}\text { Inventory to Sales (and changes in it) } \\
\text { (Kaminski, Wetzel, and Guan 2004; Summers and Sweeney 1998) }\end{array}$ & $\mathrm{O}$ \\
\hline V9 & Was Last-In, First-Out (LIFO) inventory valuation used? (Fanning and Cogger 1998) & $\mathrm{P}$ \\
\hline V10 & $\begin{array}{l}\text { Sales Growth (asset growth has also been used with the same rationale) (Beneish } \\
\text { 1997; Green and Choi 1997; Beneish 1999a; Lin, Hwang, and Becker 2003; Brazel, } \\
\text { Jones, and Zimbelman 2009; Erickson, Hanlon, and Maydew 2006; Perols and } \\
\text { Lougee 2011; Fanning and Cogger 1998) }\end{array}$ & $\mathrm{O}, \mathrm{P}$ \\
\hline V11 & $\begin{array}{l}\text { Sales to Total Assets (and changes in it) (Persons 1995; Fanning and Cogger 1998; } \\
\text { Kaminski, Wetzel, and Guan 2004; Whiting et al. 2012) }\end{array}$ & $\mathrm{O}, \mathrm{P}$ \\
\hline V12 & $\begin{array}{l}\text { Change in Gross Margin to Sales (Green and Choi 1997; Beneish 1999a; Lin, } \\
\text { Hwang, and Becker 2003; Fanning and Cogger 1998) }\end{array}$ & $\mathrm{P}$ \\
\hline V13 & Change in Cash Sales (Dechow et al. 2011; Beneish 1997) & $\mathrm{P}$ \\
\hline V14 & $\begin{array}{l}\text { Were any sales from acquisitions? (Erickson, Hanlon, and Maydew 2006; Brazel, } \\
\text { Jones, and Zimbelman 2009) }\end{array}$ & $\mathrm{P}$ \\
\hline \multicolumn{3}{|c|}{ Financial Variables: General-Asset Composition } \\
\hline $\mathrm{V} 15$ & Current Assets to Total Assets (Persons 1995) & $\mathrm{O}$ \\
\hline V16 & $\begin{array}{l}\text { Net Property Plant \& Equipment (PP\&E) to Total Assets } \\
\text { (Fanning and Cogger 1998; Kaminski, Wetzel, and Guan 2004) }\end{array}$ & $\mathrm{O}$ \\
\hline V17 & $\begin{array}{l}\text { Assets other than Cash and Net PP\&E to Total Assets } \\
\text { (Dechow et al. 2011) }\end{array}$ & $\mathrm{O}$ \\
\hline V18 & $\begin{array}{l}\text { Change in Assets other than Current Assets and Net PP\&E to Total Assets } \\
\text { (Beneish 1999a) }\end{array}$ & $\mathrm{O}$ \\
\hline \multicolumn{3}{|c|}{ Financial Variables: General-Accrual Measures } \\
\hline V19 & $\begin{array}{l}\text { Total Accruals to Total Assets } \\
\text { (Beneish 1997, 1999a; Brazel, Jones, and Zimbelman 2009; Whiting et al. 2012) }\end{array}$ & $\mathrm{O}$ \\
\hline $\mathrm{V} 20$ & Were the specified and the prior year's Total Accruals $>0$ ? (Beneish 1997) & $\mathrm{O}, \mathrm{P}$ \\
\hline V21 & RSST (unadjusted) Accruals (Richardson et al. 2005; Dechow et al. 2011) & $\mathrm{O}, \mathrm{P}$ \\
\hline V22 & Total Discretionary Accruals (Perols 2011; Perols and Lougee 2011) & $\mathrm{O}, \mathrm{P}, \mathrm{R}$ \\
\hline \multicolumn{3}{|c|}{ Financial Variables: General - Level of Debt and Financial Distress } \\
\hline V23 & $\begin{array}{l}\text { Debt to Total Assets (Persons 1995; Dechow, Sloan, and Sweeney 1996; Beneish } \\
\text { 1997; Lee, Ingram, and Howard 1999; Brazel, Jones, and Zimbelman 2009; Alden et } \\
\text { al. 2012) }\end{array}$ & $\mathrm{O}, \mathrm{P}$ \\
\hline V24 & Debt to Equity (Fanning and Cogger 1998; Erickson, Hanlon, and Maydew 2006) & $\mathrm{O}, \mathrm{P}$ \\
\hline
\end{tabular}

This is the peer reviewed version of the following article: Gepp, A., Kumar, K., \& Bhattacharya, S. (2020). Lifting the Numbers Game: Identifying key input variables and a best-performing model to detect financial statement fraud. Accounting and Finance, which has been published in final form at https://doi.org/10.1111/acfi.12742.

This article may be used for non-commercial purposes in accordance with Wiley Terms and Conditions for Use of Self-Archived Versions. 


\begin{tabular}{|c|c|c|}
\hline ID & Variable (study(-ies) that provide empirical findings to substantiate their inclusion) & FT Factor(s) \\
\hline V25 & $\begin{array}{l}\text { Altman's (1968) financial distress measure (Z-score) } \\
\text { (Feroz et al. 2000; Erickson, Hanlon, and Maydew 2006) }\end{array}$ & $\mathrm{O}, \mathrm{P}$ \\
\hline V26 & Four-period average of Times Interest Earned (Feroz et al. 2000) & $\mathrm{O}, \mathrm{P}$ \\
\hline \multicolumn{3}{|c|}{ Financial Variables: General - Performance and Profitability } \\
\hline V27 & $\begin{array}{l}\text { Return on Equity (and comparison to industry average) } \\
\text { (Feroz et al. 2000; Alden et al. 2012) }\end{array}$ & $\mathrm{P}$ \\
\hline V28 & $\begin{array}{l}\text { Return on Average Prior Assets (and changes in it) } \\
\text { (Lee, Ingram, and Howard 1999; Brazel, Jones, and Zimbelman 2009; Perols and } \\
\text { Lougee 2011; Summers and Sweeney 1998; Erickson, Hanlon, and Maydew 2006; } \\
\text { Dechow et al. 2011) }\end{array}$ & $\mathrm{P}$ \\
\hline V29 & One-Year Holding Period Return (Beneish 1999b; Dechow et al. 2011) & $\mathrm{P}$ \\
\hline V30 & $\begin{array}{l}\text { Were analyst Earnings Per Share forecasts achieved or exceeded? } \\
\text { (Perols 2011; Perols and Lougee 2011) }\end{array}$ & $\mathrm{P}$ \\
\hline \multicolumn{3}{|c|}{ Financial Variables: General - Financing } \\
\hline V31 & $\begin{array}{l}\text { Were New Securities issued? (Common Stock or Long-term Debt) } \\
\text { (Dechow, Sloan, and Sweeney 1996; Lee, Ingram, and Howard 1999; Dechow et al. } \\
\text { 2011) }\end{array}$ & $\mathrm{P}$ \\
\hline V32 & $\begin{array}{l}\text { Proportion of common stock that is newly issued (Dechow, Sloan, and Sweeney } \\
\text { 1996) }\end{array}$ & $\mathrm{P}$ \\
\hline V33 & $\begin{array}{l}\text { Was there demand for financing in the near term? } \\
\text { (Dechow, Sloan, and Sweeney 1996; Erickson, Hanlon, and Maydew 2006; } \\
\text { Skousen, Smith, and Wright 2009) }\end{array}$ & $\mathrm{P}$ \\
\hline V34 & Were there operating leases? (Dechow et al. 2011) & $\mathrm{R}$ \\
\hline \multicolumn{3}{|c|}{ Non-financial Variables - Key Roles and Responsibilities } \\
\hline V35 & $\begin{array}{l}\text { Was the auditor a Big Four (Six) firm? } \\
\text { (Perols 2011; Fanning and Cogger 1998; Carcello and Nagy 2004) }\end{array}$ & $\mathrm{O}$ \\
\hline V36 & $\begin{array}{l}\text { Turnover or tenure of the external audit firm (Feroz et al. 2000; Perols 2011; } \\
\text { Carcello and Nagy 2004; McKee 2009) }\end{array}$ & $\mathrm{O}, \mathrm{R}$ \\
\hline V37 & $\begin{array}{l}\text { CEO Tenure / number of changes in CEO (Feroz et al. 2000; Ndofor, Wesley, and } \\
\text { Priem 2015), where the latter citation studies financial restatements, which are } \\
\text { related to but different from financial statement fraud }\end{array}$ & $\mathrm{O}$ \\
\hline V38 & Number of changes in CFO (Fanning and Cogger 1998) & $\mathrm{O}$ \\
\hline V39 & $\begin{array}{l}\text { Composition/Holdings of the Board of Directors } \\
\text { (Beasley 1996; Carcello and Nagy 2004; Dechow, Sloan, and Sweeney 1996) }\end{array}$ & $\mathrm{O}$ \\
\hline V40 & Proportion of total shares owned by the CEO* (Johnson, Ryan, and Tian 2009) & $\mathrm{P}$ \\
\hline \multicolumn{3}{|c|}{ Variables Comparing Financial and Non-financial Information } \\
\hline V41 & $\begin{array}{l}\text { Change in the number of Employees minus Change in Total Assets } \\
\text { (Dechow et al. 2011) }\end{array}$ & \multirow{3}{*}{$\begin{array}{l}\text { Suspicious if } \\
\text { large, but not } \\
\text { linked to a FT } \\
\text { driver of fraud }\end{array}$} \\
\hline V42 & $\begin{array}{l}\text { Change in Sales minus Change in the number of Employees } \\
\text { (Brazel, Jones, and Zimbelman 2009) }\end{array}$ & \\
\hline V43 & $\begin{array}{l}\text { Change in Sales to Employees (relative to industry average) } \\
\text { (Perols and Lougee 2011; Perols 2011) }\end{array}$ & \\
\hline \multicolumn{3}{|c|}{ Control Variables } \\
\hline V44 & $\begin{array}{l}\text { Company Age } \\
\text { (Lee, Ingram, and Howard 1999; Carcello and Nagy 2004; Erickson, Hanlon, and } \\
\text { Maydew 2006; Brazel, Jones, and Zimbelman 2009) }\end{array}$ & $\mathrm{P}$ \\
\hline V45 & Company Size (natural log of Total Assets) (Persons 1995; McKee 2009) & $\mathrm{O}$ \\
\hline V46 & Standard Industrial Classification (Lee, Ingram, and Howard 1999) & $\mathrm{O}, \mathrm{P}$ \\
\hline V47 & $\begin{array}{l}\text { Stock Exchange listed on (NASDAQ, NYSE or AMEX) (Lee, Ingram, and Howard } \\
\text { 1999) }\end{array}$ & $\mathrm{O}$ \\
\hline \multicolumn{3}{|c|}{ New Variables } \\
\hline V48 & Macroeconomic Indicators (change in real GDP, unemployment, retail sales) & $\mathrm{O}, \mathrm{P}$ \\
\hline V49 & Corporate Governance Index: G-Index (Gompers, Ishii, and Metrick 2003) & $\mathrm{O}$ \\
\hline V50 & Accounting complexity of the industry (Seavey 2011) & $\mathrm{O}$ \\
\hline
\end{tabular}

This is the peer reviewed version of the following article: Gepp, A., Kumar, K., \& Bhattacharya, S. (2020). Lifting the Numbers Game: Identifying key input variables and a best-performing model to detect financial statement fraud. Accounting and Finance, which has been published in final form at https://doi.org/10.1111/acfi.12742.

This article may be used for non-commercial purposes in accordance with Wiley Terms and Conditions for Use of Self-Archived Versions. 
Table 4. The corresponding prior-adjusted relative cost of missing fraud $\left(\mathrm{PaRC} \mathrm{C}_{I F}\right)$ for each combination of ratio of error cost and prior probability of fraud.

\begin{tabular}{|l|c|c|c|c|}
\hline \multirow{2}{*}{$\begin{array}{l}\text { Ratio of Error Costs }\left(\boldsymbol{C}_{\boldsymbol{I F}}: \boldsymbol{C}_{\boldsymbol{I}}\right) \\
\text { (missing fraud: falsely alleging fraud) }\end{array}$} & \multicolumn{4}{|c|}{ Prior probability of fraud $[\boldsymbol{p}(\boldsymbol{F})]$} \\
\cline { 2 - 5 } & $\mathbf{0 . 4 0 \%}$ & $\mathbf{1 . 0 0 \%}$ & $\mathbf{5 . 5 0 \%}$ & $\mathbf{1 4 . 5 0 \%}$ \\
\hline $\mathbf{1 : 1}$ & 0.004 & 0.01 & 0.1 & 0.2 \\
\hline $\mathbf{1 0 : 1}$ & 0.04 & 0.1 & 0.6 & 2 \\
\hline $\mathbf{2 0 : 1}$ & 0.1 & 0.2 & 1 & 3 \\
\hline $\mathbf{3 0 : 1}$ & 0.1 & 0.3 & 2 & 5 \\
\hline $\mathbf{4 0 : 1}$ & 0.2 & 0.4 & 2 & 7 \\
\hline $\mathbf{5 0 : 1}$ & 0.2 & 0.5 & 3 & 8 \\
\hline $\mathbf{6 0 : 1}$ & 0.2 & 0.6 & 3 & 10 \\
\hline $\mathbf{1 0 0 : 1}$ & 0.4 & 1 & 6 & 17 \\
\hline
\end{tabular}

This is the peer reviewed version of the following article: Gepp, A., Kumar, K., \& Bhattacharya, S. (2020). Lifting the Numbers Game: Identifying key input variables and a best-performing model to detect financial statement fraud. Accounting and Finance, which has been published in final form at https://doi.org/10.1111/acfi.12742. 
Table 5. Summary of the models developed in this research.

\begin{tabular}{|c|c|}
\hline Model Code & Model Details \\
\hline \multicolumn{2}{|c|}{ Benchmark Models as estimated in prior research } \\
\hline M-score & Probit analysis model developed by Beneish $(1997,1999 a)$ \\
\hline F-score & Stepwise logistic regression Model $2^{2}$ developed by Dechow et al. (2011) \\
\hline \multicolumn{2}{|c|}{ Standard Regression-based Models: Discriminant Analysis (DA) and Logistic Regression (LR) } \\
\hline DA_All & Inclusion of all available variables (except the missing value exclusion) \\
\hline DA_U15\% & Only variables statistically significant at the $15 \%$ level in univariate tests \\
\hline DA_U15\%LR & Only variables statistically significant at the $15 \%$ level in the LR_U15\% model \\
\hline DA_Step & Stepwise variable selection \\
\hline LR_All & Inclusion of all variables (except the missing value exclusion) \\
\hline LR_U15\% & Only variables statistically significant at the $15 \%$ level in univariate tests \\
\hline LR_U15\%LR & Only variables statistically significant at the $15 \%$ level in the LR_U15\% model \\
\hline LR_Step & Stepwise variable selection \\
\hline LR_MS_S & Multi-stage LR model using the categories of explanatory variables \\
\hline \multicolumn{2}{|c|}{ Artificial Neural Networks (NN) and Support Vector Machine (SVM) } \\
\hline NN_BK & Backpropagation neural network with 1 hidden layer containing 4 neurons \\
\hline NN_GA_1 & \multirow{2}{*}{$\begin{array}{l}\text { Backpropagation neural network optimized by a genetic algorithm with a minimum } \\
\text { learning rate of } 0.1 \text { (NN_GA_1) or } 0.5 \text { (NN_GA_5) }\end{array}$} \\
\hline NN_GA_5 & \\
\hline SVM_L5 & Linear kernel with $\mathrm{c}=5$ as determined by grid search on cross-validated training data \\
\hline \multicolumn{2}{|c|}{ Decision Trees (DTs) and Ensembles of them: Random Forests (RF) and TreeNet (TN) } \\
\hline DT_Suite & Suite of cost-sensitive CART decision trees, one for each value of $P a R C_{I F}$ \\
\hline DT_One & One cost-insensitive CART decision tree used for all values of $P a R C_{I F}$ \\
\hline RF_8 & Random Forests with 1000 trees and variable subset size of 8 \\
\hline RF_66 & Random Forests with 1000 trees and variable subset size of 66 \\
\hline $\mathrm{TN}$ & TreeNet with 1184 trees, 0.01 learning rate and a maximum of 12 nodes per tree \\
\hline \multicolumn{2}{|c|}{ Ensembles involving multiple modelling techniques } \\
\hline NN_LR & NN_BK classifications included as an additional explanatory variable in LR_All \\
\hline DT_LR & DT_One classifications included as an additional explanatory variable in LR_All \\
\hline DTnode_LR_Step & $\begin{array}{l}\text { Terminal node assignments from DT_One included as an additional input variables in } \\
\text { the LR_Step model }\end{array}$ \\
\hline $\begin{array}{l}\text { NN- } \\
\text { DTnode_LR_Step }\end{array}$ & $\begin{array}{l}\text { NN_BK classifications included as an additional explanatory variable in the } \\
\text { DTnode_LR_Step model }\end{array}$ \\
\hline Vote5 & Majority Vote between DT_One, TN, RF_8, NN_BK and LR_All \\
\hline Vote3_RF_TN_DT & Majority Vote between TN, RF_8 and DT_One \\
\hline Vote3_RF_TN_DA & Majority Vote between TN, RF_8 and DA_All \\
\hline Vote3_RF_TN_NN & Majority Vote between TN, RF_8 and NN_BK \\
\hline AV5_NoNN & Average between DT_One, TN, RF_8, LR_All and DA_All \\
\hline AV2_RF_TN & Average between TN and RF_8 \\
\hline AV3_RF_TN_DT & Average between TN, RF_8 and DT_One \\
\hline DT_One_DA & $\begin{array}{l}\text { Discriminant analysis (based on DA_All) performed as a second stage on the riskier } \\
\text { classifications from DT_One }\end{array}$ \\
\hline
\end{tabular}

${ }^{2}$ Model 2 was chosen because it includes non-financial variables and it excludes two variables requiring an estimate of the "annual buy-and-hold value-weighted market return", because there is some ambiguity to its calculation.

This is the peer reviewed version of the following article: Gepp, A., Kumar, K., \& Bhattacharya, S. (2020). Lifting the Numbers Game: Identifying key input variables and a best-performing model to detect financial statement fraud. Accounting and Finance, which has been published in final form at https://doi.org/10.1111/acfi.12742.

This article may be used for non-commercial purposes in accordance with Wiley Terms and Conditions for Use of Self-Archived Versions. 
Table 6. The holdout performance of the best models compared to the benchmark models.

\begin{tabular}{|c|c|c|c|}
\hline \multirow[b]{2}{*}{$\operatorname{PaRC}_{I F}$} & \multicolumn{2}{|c|}{$\begin{array}{l}\text { Improvement in WEC of the Best } \\
\text { model overall (AV5_NoNN) compared to }\end{array}$} & \multirow{2}{*}{$\begin{array}{l}\text { Further improvement in } \\
\text { WEC of the Best model for } \\
\text { each value of } \operatorname{PaRC}_{I F} \\
\text { (compared to AV5_NoNN) }\end{array}$} \\
\hline & M-score & F-score & \\
\hline 0.004 & $60 \%$ lower WEC & $1 \%$ lower WEC & $2 \%$ \\
\hline 0.01 & $38 \%$ lower WEC & $1 \%$ lower WEC & $2 \%$ \\
\hline 0.04 & 14\% lower WEC & $1 \%$ lower WEC & $2 \%$ \\
\hline 0.1 & $8 \%$ lower WEC & $2 \%$ lower WEC & $1 \%$ \\
\hline 0.2 & $9 \%$ lower WEC & 7\% lower WEC & $0 \%$ \\
\hline 0.3 & 9\% lower WEC & $8 \%$ lower WEC & $1 \%$ \\
\hline 0.4 & $15 \%$ lower WEC & $14 \%$ lower WEC & $6 \%$ \\
\hline 0.5 & $18 \%$ lower WEC & $23 \%$ lower WEC & $8 \%$ \\
\hline 0.6 & $22 \%$ lower WEC & 24\% lower WEC & $10 \%$ \\
\hline 1 & $37 \%$ lower WEC & $39 \%$ lower WEC & $2 \%$ \\
\hline 2 & $23 \%$ lower WEC & $17 \%$ lower WEC & $0 \%$ \\
\hline 3 & $5 \%$ lower WEC & 9\% lower WEC & $5 \%$ \\
\hline 5 & Equal WEC & Equal WEC & $0 \%$ \\
\hline 6 & $1 \%$ higher WEC & $1 \%$ higher $\mathrm{WEC}$ & $11 \%$ \\
\hline 7 & $2 \%$ higher $\mathrm{WEC}$ & $2 \%$ higher WEC & $10 \%$ \\
\hline 8 & $6 \%$ lower WEC & $6 \%$ lower WEC & $1 \%$ \\
\hline 10 & 4\% lower WEC & $4 \%$ lower WEC & $9 \%$ \\
\hline 17 & $1 \%$ lower WEC & $1 \%$ lower WEC & $11 \%$ \\
\hline
\end{tabular}

This is the peer reviewed version of the following article: Gepp, A., Kumar, K., \& Bhattacharya, S. (2020). Lifting the Numbers Game: Identifying key input variables and a best-performing model to detect financial statement fraud. Accounting and Finance, which has been published in final form at https://doi.org/10.1111/acfi.12742. 
Table 7. A comparison of the holdout performance of different ensemble models.

\begin{tabular}{|c|c|c|c|c|}
\hline \multirow[b]{2}{*}{ Model } & \multicolumn{3}{|c|}{$\begin{array}{l}\text { WEC Measure across all values of } \boldsymbol{P a R C _ { I F }} \\
\text { (Ranking: } 1 \text { is best }-5 \text { is worst) }\end{array}$} & \multirow{2}{*}{$\begin{array}{c}\text { Final } \\
\text { Average } \\
\text { Rank }\end{array}$} \\
\hline & $\mathrm{WEC}<1$ & Lowest WEC & Average Rank & \\
\hline AV5_NoNN & 15 (rank 1) & 8 (rank 1) & $2.0($ rank 1) & 1 \\
\hline Vote3 RF TN DT & 11 (rank 2) & $4(\operatorname{rank} 2)$ & 2.5 (rank 2) & 2 \\
\hline $\mathrm{TN}$ & 11 (rank 2) & 3 (rank 4) & 2.7 (rank 3) & 3 \\
\hline RF 66 & $9(\operatorname{rank} 4)$ & $4(\operatorname{rank} 2)$ & 3.7 (rank 5) & 3.67 \\
\hline DT One DA & $3(\operatorname{rank} 5)$ & $1(\operatorname{rank} 5)$ & 3.4 (rank 4) & 4.67 \\
\hline
\end{tabular}


Table 8. The coefficients of variables in logistic regression models with the dependent variable being fraud (1) or legitimate (0). For each increase by one in a variable, the odds of a financial statement being fraudulent change by $e^{\beta}-1$, holding constant all other variables. For example, for each increase in V33 by one, the odds of a financial statement being fraudulent decrease by $45 \%$ * indicates at a $5 \%$ level and $* *$ indicates at a $1 \%$ level using the Wald test statistic.

\begin{tabular}{|l|l|c|c|c|}
\hline ID & Variable & Coefficient $(\boldsymbol{\beta})$ & $\boldsymbol{e}^{\boldsymbol{\beta}}-\mathbf{1}$ & $\mathbf{p}$-value \\
\hline V8 & Inventory to Sales & $2.785^{* *}$ & $1520 \%$ & 0.0049 \\
\hline V11 & Sales to Total Assets & $-0.412^{* *}$ & $-34 \%$ & 0.0012 \\
\hline V19 & Total Accruals to Total Assets & $1.266^{*}$ & $255 \%$ & 0.0499 \\
\hline V20 & Were the specified and the prior year's Total Accruals $>0 ?$ & $1.564^{* *}$ & $378 \%$ & 0.0001 \\
\hline V24 & Debt to Equity & $-0.083^{* *}$ & $-8 \%$ & 0.0001 \\
\hline V27 & Return on Equity & $-0.772^{* *}$ & $-54 \%$ & 0.0002 \\
\hline V28 & Return on Average Prior Assets & $0.886^{*}$ & $143 \%$ & 0.0421 \\
\hline V31 & Was New Common Stock or Long-term Debt Issued? & $1.383^{* *}$ & $299 \%$ & 0.0005 \\
\hline V33 & Demand for financing (ex ante) & $-0.589^{* *}$ & $-45 \%$ & 0.0045 \\
\hline V34 & Were there operating leases? & $0.737^{* *}$ & $109 \%$ & 0.0063 \\
\hline V39 & Percentage of Directors who are also Executives & $1.394^{*}$ & $303 \%$ & 0.0445 \\
\hline V44 & Company Age: Number of years since foundation & $-0.010^{* *}$ & $-1 \%$ & 0.0002 \\
\hline V45 & Company Size: natural log of Total Assets & $0.389^{* *}$ & $48 \%$ & 0.0000 \\
\hline V46 & Industry: SIC code starts with a 3? & $-0.486^{*}$ & $-38 \%$ & 0.0373 \\
\hline \hline Constant & & -3.966 & $-98 \%$ & 0.0000 \\
\hline
\end{tabular}

This is the peer reviewed version of the following article: Gepp, A., Kumar, K., \& Bhattacharya, S. (2020). Lifting the Numbers Game: Identifying key input variables and a best-performing model to detect financial statement fraud. Accounting and Finance, which has been published in final form at https://doi.org/10.1111/acfi.12742. 
Table 9. Key variables influencing financial statement fraud according to the factors of the Fraud Triangle (FT).

\begin{tabular}{|c|c|c|}
\hline & \multicolumn{2}{|c|}{ The probability of financial statements being fraudulent increases with } \\
\hline FT Factor & Lower levels of... & Higher levels of... \\
\hline $\mathrm{O}$ & $\begin{array}{l}\text { Debt to Equity } \\
\text { more corporate governance initiatives } \\
\text { (indicated by larger G-Index values) }\end{array}$ & $\begin{array}{c}\text { Inventory to Sales } \\
\text { Total Accurals to Total Assets } \\
\text { Percentage of directors who are also executives }\end{array}$ \\
\hline $\mathrm{O}$ and $\mathrm{P}$ & & Positive total accruals (current $\&$ prior) \\
\hline $\mathrm{P}$ & $\begin{array}{l}\text { Return on Equity } \\
\text { Sales to Total Assets } \\
\text { Company age }\end{array}$ & $\begin{array}{c}\text { New equity or long-term debt having been issued } \\
\text { Demand for financing (ex ante) }\end{array}$ \\
\hline $\mathrm{R}$ & & The use of operating leases \\
\hline \multicolumn{2}{|c|}{ Suspicious if large, but not linked to an FT Factor } & Return on Average Prior Assets \\
\hline
\end{tabular}

This is the peer reviewed version of the following article: Gepp, A., Kumar, K., \& Bhattacharya, S. (2020). Lifting the Numbers Game: Identifying key input variables and a best-performing model to detect financial statement fraud. Accounting and Finance, which has been published in final form at https://doi.org/10.1111/acfi.12742. 


\section{A.1 Standard Regression-based Models}

The models are based on prior studies and differ with the selection of input variables:

- All variables (Lee, Ingram, and Howard 1999; Kaminski, Wetzel, and Guan 2004; Bayley and Taylor 2007);

- Statistically significant variables at a $15 \%$ level in univariate tests and logistic regression (Skousen, Smith, and Wright 2009; Skousen and Wright 2008);

- Variables selected by stepwise techniques (Persons 1995; Bell and Carcello 2000; Dechow et al. 2011) with the level of significance for entry and exit set at $5 \%$ and $10 \%$ respectively.

- A new multi-stage logistic regression model using variable categories from Figure 3 (based on the Summers and Sweeney (1998) model). In the first stage, five logistic regression models are estimated, each using input variables from a different category. In the second stage, the LR_MS_S model uses Pr(F) Financial, $\operatorname{Pr}(\mathrm{F})_{\text {Non-Financial }}, \operatorname{Pr}(\mathrm{F})_{\text {Comparison }}, \operatorname{Pr}(\mathrm{F})_{\text {Control }}$ and $\operatorname{Pr}(\mathrm{F})_{\text {New }}$ as input variables, where $\operatorname{Pr}(\mathrm{F})_{x}$ is the probability of fraud estimated from the first stage with input variables from the $x$ category.

A major shortcoming of parametric models such as logistic regression is that they are susceptible to multicollinearity. Although the variable selection used in the models above partly addresses this issue, it remains one of the most important technical reasons for preferring non-parametric models for financial statement fraud detection, as many of the financial input variables based on accounting data (as well as some non-financial variables) tend to be substantially correlated. As non-parametric models are not restrained by the parametric assumptions of generalized linear models, they are expected to work better relative to logistic regression and similar parametric models in such a case where multi-collinearity is likely an issue.

\section{A.2 Artificial Neural Network (ANN) Models}

ANN models are built using all input variables, because they are better than standard regression-based models at selecting important variables. Consistent with past research, each explanatory variable is normalized to range between 0 and 1 , by subtracting the minimum value and then dividing by the range. Based on use in prior literature, a feed-forward backpropagation network was chosen with one hidden layer and that uses sigmoid for both activation and transfer functions. The following parameters were chosen based on optimization using the training data: learning rate of 0.5 , momentum of 0.1 , and four neurons in the hidden layer. IBM's SPSS Statistics" "Multilayer Perceptron" model was used to develop this model.

ANNs with parameters optimized by genetic algorithm (GA) have also been developed, because this process is likely to be most efficient in optimizing ANNs (Bhattacharya, Xu, and Kumar 2011). Encouraging results

This is the peer reviewed version of the following article: Gepp, A., Kumar, K., \& Bhattacharya, S. (2020). Lifting the Numbers Game: Identifying key input variables and a best-performing model to detect financial statement fraud. Accounting and Finance, which has been published in final form at https://doi.org/10.1111/acfi.12742. 
have also been found using a similar approach in a prior study (Fanning and Cogger 1998). The software Neuralyst (version 1.4) was used to develop GA-optimized ANN models (noted as NN_GA). These ANNs still used backpropagation and sigmoid functions while the genetic algorithm optimized variable selection and the learning parameters of the ANN. The Neuralyst default value for the minimum learning rate is 0.5 , which is greater than the lowest value of 0.1 used in prior research (Green and Choi 1997; Perols 2011). Consequently, two models were developed, one for each of these parameters.

It is important to note that when training any $\mathrm{ANN}$, one of the biggest challenges is avoiding over-learning, which is analogous to the problem of 'curve-fitting' in linear regression models. Complex ANN architectures can be prone to over-learning whereby the network performs very well on the training data, but the predictive performance falls sharply for the holdout data. Consequently, in accordance with the principle of parsimony, the simplest possible architecture of only one hidden layer was initially used. Other multi-layer architectures could then have been trialled for a performance gain, but such a process would be computationally inefficient if carried out heuristically. However, a GA-based approach removes the need to rely on heuristics to evaluate different architectures (Bhattacharya, $\mathrm{Xu}$, and Kumar 2011). As a result, such an approach was adopted to determine the best network architecture for the pattern search problem at hand. In essence, the NN_GA models ran a variety of architectures over many generations to determine which architecture survived via a process of natural selection, thus establishing itself as the evolutionarily optimized one. For both learning rates, the resulting architecture had two hidden layers, the first with 30 neurons and the second with 10 neurons.

\section{A.3 Support Vector Machine (SVM)}

Although not extensively, SVMs have been used in prior fraud detection literature (Ngai et al. 2011). SVMs have also shown promise in detecting financial statement fraud using US data (Perols 2011), but unfortunately no details about the parameters of the SVM were provided and so modelling insights are limited. The popular scikit-learn Python library was used to train the SVM used in this research. All input variables are used in the process as SVMs possess a natural variable selection ability. As for ANN models, all variables were normalized. As parameter setting can be important, they were empirically selected by grid search. Linear, polynomial radial basis function and sigmoid kernels were trialled, along with $\mathrm{c}$ values in 0.25 increments, where $\mathrm{c}$ is the penalty parameter for the error term. Ten-fold cross-validation on the training data revealed that a linear kernel with $\mathrm{c}$ equal to 3 performed best and so was used to develop the SVM model on the full training data.

This is the peer reviewed version of the following article: Gepp, A., Kumar, K., \& Bhattacharya, S. (2020). Lifting the Numbers Game: Identifying key input variables and a best-performing model to detect financial statement fraud. Accounting and Finance, which has been published in final form at https://doi.org/10.1111/acfi.12742. 
As a SVM does not inherently produce probabilities of class membership, but only the classifications, probabilities were calculated using Platt scaling (Platt 1999) to enable cut-off values to be optimized for each $P a R C_{I F}$ scenario. Using the classification output of the SVM without cut-off optimization was considered, but it did not result in improved performance and so was not utilized.

\section{A.4 Individual Decision Tree Models}

There is a lack of research that uses decision-tree techniques, particularly CART decision trees that have performed well on a Chinese data set (Bai, Yen, and Yang 2008) and have performed better than other decision trees in other classification problems in business. Consequently, CART trees are developed in this study using version 7 of Salford Predictive Modeler by Salford Systems. CART trees are grown to their full extent and then pruned to obtain the tree with the lowest WEC as determined by cross-validation on the training data. CART trees can handle missing values using surrogate splits, which may assist in improving accuracy, and so this approach was adopted.

The best parameter settings for CART decision trees were empirically determined by thousands of crossvalidated trials on the training data set. Two final models using CART decision trees have been developed. The first, DT_Mult, is a suite of optimized trees, one for each value of $\operatorname{PaR} C_{I F}$. However, it is not certain that differences in these parameters result in substantially improved performance. Therefore, in order to investigate the value of developing a decision tree for each value of $P a R C_{I F}$, a second model, DT_One, was developed, using the optimized tree when $P a R C_{I F}=1$ in all cases. This optimized tree used the Gini splitting criterion.

\section{A.5 Ensembles of Decision Trees: Random Forests and TreeNet}

Advantages of decision trees include being non-parametric, resistant to outliers and irrelevant variables and being able to model interactions similar to ANNs, but in contrast they are also transparent, easy to represent visually and simpler to interpret. They also do not require variable transformations because monotonic transformations do not influence the model. However, one major disadvantage of decision trees is that they are sensitive to small changes in the training data, which is a particular problem since fraud data are not $100 \%$ accurate. Newer ensemble techniques use multiple trees to overcome this issue and provide more stable and robust models with reduced variance, and often increased accuracy. Random Forests and stochastic gradient boosting are examples of such ensemble techniques that have shown promise in detecting financial statement fraud. However, in prior studies neither has been tested using a separate holdout sample or over a range of varying ratios of error costs, which is what has been done in this research.

This is the peer reviewed version of the following article: Gepp, A., Kumar, K., \& Bhattacharya, S. (2020). Lifting the Numbers Game: Identifying key input variables and a best-performing model to detect financial statement fraud. Accounting and Finance, which has been published in final form at https://doi.org/10.1111/acfi.12742. 
The same software used for decision trees has been used in this study, where TreeNet is the program used to perform stochastic gradient boosting. For both methods, creating individual models for each value of $P a R C_{I F}$ was briefly investigated, but it did not result in improved performance and so was not utilized. The main parameters for each model (as listed in Table 4 above) were determined by empirical evaluation of trial values on the training data. The choice of trial values was guided by past research where it existed.

\section{A.6 Ensembles involving multiple modelling techniques}

In addition to ensembles of decision trees, ensemble models involving multiple modelling techniques have been developed. The first two ensemble models (NN_LR and DT_LR) have been included based on prior work (McKee 2009). New ensembles (DTnode_LR_Step and NN-DTnode_LR_Step) were then developed based on a different ordering of the underlying techniques to better use their individual advantages. Specifically, neural networks and decision trees are used to initially model nonlinear effects and then logistic regression is used at the last stage to produce a probability of fraud that is continuous.

Combining techniques using a Majority Vote (noted as VOTE) has shown promise on Greek and Chinese data (e.g. (Kotsiantis et al. 2007)). In a Majority Vote, the final classification is determined as the classification that has been assigned the most times (the mode) by a set of underlying models. An odd number of underlying models (three or five) is used to remove the possibility of a tied vote. Majority Vote works well when the underlying models are diverse, so the choice of underlying models took this into account as well as performance on the training data.

Ensembles are also developed by averaging the probability of fraud outputs from a set of underlying models (noted as AV). The resulting average probability is then compared to the averaged cut-off values to obtain a classification. This technique also had encouraging results when used on Greek data (Kotsiantis et al. 2007). Unlike Majority Vote, there is no reason to have an odd number of underlying models, and the averaging process is not adversely influenced by including highly correlated models. Consequently, the underlying models were chosen purely based on empirical performance using trials on the training data.

The final model, DT_One_DA, was motivated by a model that performed well at classifying customers likely to churn in the telecommunications industry (Nagadevara 2010), but has not before been evaluated in this context.

This is the peer reviewed version of the following article: Gepp, A., Kumar, K., \& Bhattacharya, S. (2020). Lifting the Numbers Game: Identifying key input variables and a best-performing model to detect financial statement fraud. Accounting and Finance, which has been published in final form at https://doi.org/10.1111/acfi.12742. 
Figures (3)

Figure 1. The Fraud Triangle framework.

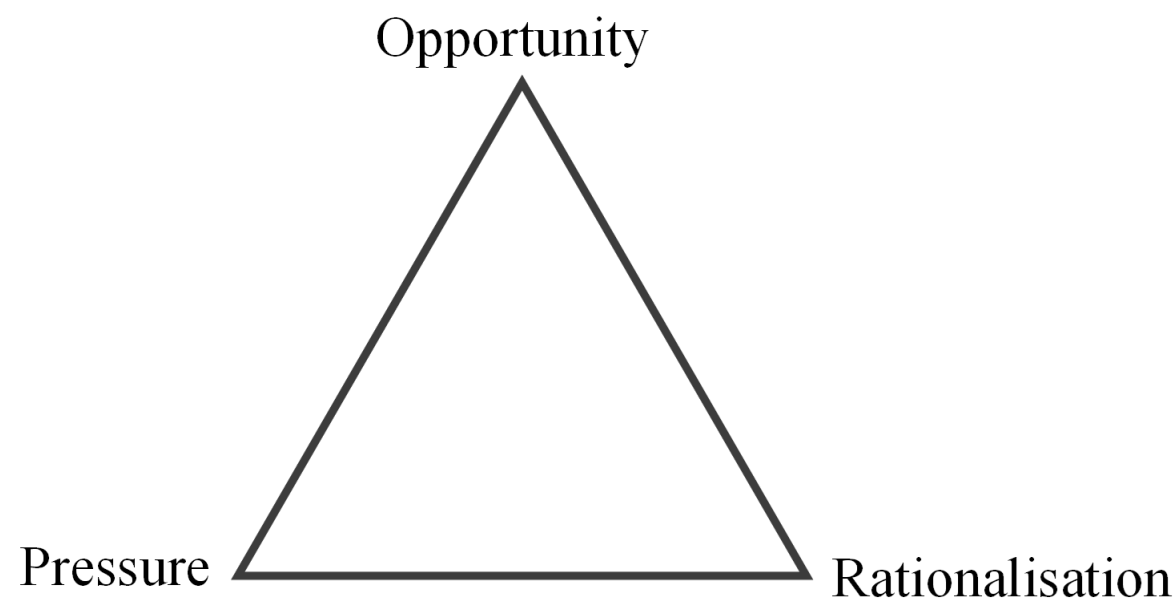

This is the peer reviewed version of the following article: Gepp, A., Kumar, K., \& Bhattacharya, S. (2020). Lifting the Numbers Game: Identifying key input variables and a best-performing model to detect financial statement fraud. Accounting and Finance, which has been published in final form at https://doi.org/10.1111/acfi.12742.

This article may be used for non-commercial purposes in accordance with Wiley Terms and Conditions for Use of Self-Archived Versions. 
Figure 2. Categories of input variables and the relationships between them. While not exactly to scale, the size of the shapes provides an indication of each category's contribution in terms of the number of variables, except for the new variables category that is disproportionately large.

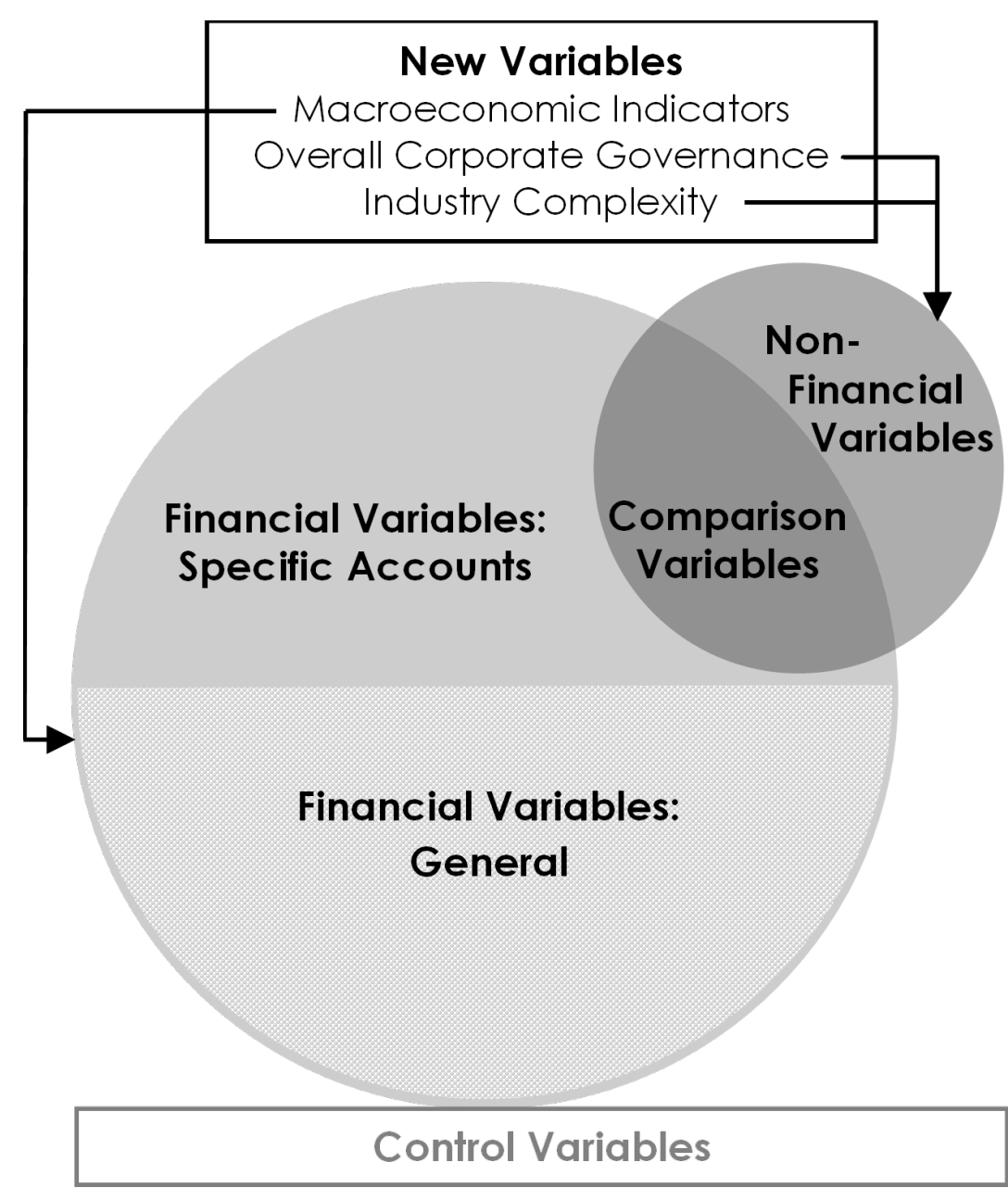


Figure 3. An illustration of how to select the best model for a given circumstance and prior probability of fraud.

\begin{tabular}{|c|c|c|c|c|c|c|c|c|c|c|}
\hline \multirow{2}{*}{$\begin{array}{l}\text { Ratio of } \\
\text { Error Costs }\end{array}$} & \multicolumn{4}{|c|}{ Prior probability of fraud } & \multirow{2}{*}{$\operatorname{PaRC}_{I F}$} & \multicolumn{4}{|c|}{$\begin{array}{l}\text { Best Model(s) with the Lowest Holdout WEC } \\
\text { F/L: Accuracy at Detecting Fraud/Legitimate }\end{array}$} & \multirow{2}{*}{$\begin{array}{l}\text { Model(s) within } \\
2 \% \text { of the Lowest WEC }\end{array}$} \\
\hline & $0.40 \%$ & $1.00 \%$ & $5.50 \%$ & $14.50 \%$ & & WEC & $\mathbf{F}$ & $\mathbf{L}$ & Model Code & \\
\hline $1: 1$ & 0.004 & 0.01 & 0.1 & 0.2 & \multirow{2}{*}{0.004} & \multirow{2}{*}{0.964} & \multirow{2}{*}{$4 \%$} & \multirow{2}{*}{$100 \%$} & \multirow{2}{*}{ DA_U15\% } & \multirow{2}{*}{$\begin{array}{l}\text { LR_U15\% (within 1\%) } \\
\text { LR_Step } \\
\text { Vote3_RF_TN_DA }\end{array}$} \\
\hline $10: 1$ & 0.04 & 0.1 & 0.6 & 2 & & & & & & \\
\hline $20: 1$ & 0.1 & 0.2 & 1 & $3)$ & \multirow[b]{2}{*}{0.01} & \multirow[b]{2}{*}{0.964} & \multirow[b]{2}{*}{$4 \%$} & \multirow[b]{2}{*}{$100 \%$} & \multirow[b]{2}{*}{ DA_U15\% } & LR_U15\% (within 1\%) \\
\hline 30:1 & 0.1 & 0.3 & 2 & 5 & & & & & & $\begin{array}{l}\text { LR_Step, } \\
\text { Vote3_RF_TN_DA }\end{array}$ \\
\hline $40: 1$ & 0.2 & 0.4 & 2 & 7 & \multirow{3}{*}{0.04} & \multirow{3}{*}{0.964} & \multirow{3}{*}{$4 \%$} & \multirow{3}{*}{$100 \%$} & \multirow{3}{*}{ DA_U15\% } & \multirow{3}{*}{$\begin{array}{l}\text { LR_U15\% (within 1\%) } \\
\text { LR_Step } \\
\text { Vote3_RF_TN_DA }\end{array}$} \\
\hline $50: 1$ & 0.2 & 0.5 & 3 & 8 & & & & & & \\
\hline $60: 1$ & 0.2 & 0.6 & 3 & 10 & & & & & & \\
\hline 100:1 & 0.4 & 1 & 6 & 17 & 0.1 & 0.970 & $3 \%$ & $100 \%$ & LR_U15\% & $\begin{array}{l}\text { AV5_NoNN (within 1\%) } \\
\text { Vote5 }\end{array}$ \\
\hline & & & & & 0.2 & 0.935 & $9 \%$ & $99 \%$ & AV5_NoNN & AV3_RF_TN_DT \\
\hline & & & & & 0.3 & 0.913 & $28 \%$ & $94 \%$ & RF_66 & AV5_NoNN \\
\hline & & & & & 0.4 & 0.805 & $28 \%$ & $96 \%$ & AV3_RF_TN_DT & \\
\hline & & & & & 0.5 & 0.763 & $50 \%$ & $87 \%$ & Vote3_RF_TN_DT & \\
\hline & & & & & 0.6 & 0.720 & $50 \%$ & $87 \%$ & Vote3_RF_TN_DT & \\
\hline & & & & & 1 & 0.580 & $66 \%$ & $76 \%$ & Vote3_RF_TN_DT & \\
\hline & & & & & 2 & 0.834 & $85 \%$ & $46 \%$ & AV5_NoNN & \\
\hline & & & & & & 0.905 & $91 \%$ & $36 \%$ & RF_66 & \\
\hline & & & & & 5 & 1.000 & $\begin{array}{c}100 \% \\
100 \% \\
100 \% \\
98 \% \\
\end{array}$ & $\begin{array}{c}0 \% \\
0 \% \\
0 \% \\
12 \% \\
\end{array}$ & $\begin{array}{l}\text { M-score / F-score } \\
\text { NN_GA_1 } \\
\text { DT_One, DT_One_DA } \\
\text { AV5_NoNN }\end{array}$ & Vote5 \\
\hline & & & & & 6 & 0.899 & $98 \%$ & $21 \%$ & \begin{tabular}{|l|} 
TN \\
Vote3_RF_TN_DT \\
\end{tabular} & \\
\hline & & & & & 7 & 0.917 & $98 \%$ & $21 \%$ & $\mathrm{TN}$ & $\begin{array}{l}\text { Vote3_RF_TN_NN } \\
\text { Vote3_RF_TN_DT }\end{array}$ \\
\hline & & & & & 8 & 0.935 & $98 \%$ & $21 \%$ & $\mathrm{TN}$ & $\begin{array}{l}\text { AV5_NoNN (within 1\%) } \\
\text { Vote3_RF_TN_DT } \\
\text { Vote3_RF_TN_NN } \\
\text { NN_LR; Vote5 } \\
\end{array}$ \\
\hline & & & & & 10 & 0.876 & $100 \%$ & $12 \%$ & RF_66 & Vote3_RF_TN_DA \\
\hline & & & & & 17 & 0.876 & $100 \%$ & $12 \%$ & RF_66 & \\
\hline
\end{tabular}

